\title{
Physicochemical Characterization of Petroleum Fractions: the State of the Art
}

\author{
I. Merdrignac ${ }^{1}$ and D. Espinat ${ }^{1}$ \\ 1 Institut français du pétrole, IFP-Lyon, BP 3, 69390 Vernaison - France \\ e-mail: isabelle.merdrignac@ifp.fr - didier espina†@ifp.fr
}

\begin{abstract}
Résumé - Caractérisation physico-chimique des produits lourds pétroliers : état de l'art - Les fractions pétrolières lourdes sont des fractions de haut point d'ébullition $\left(350^{\circ} \mathrm{C}^{+}\right)$enrichies en composés les plus polaires tels que les résines et les asphaltènes. Les asphaltènes contiennent une multitude de molécules d'aromaticité variable et dont les teneurs en hétéroatomes, métaux et groupements fonctionnels sont différentes. Les asphaltènes constituent un milieu hétérogène de molécules dispersées en terme de taille et de composition chimique. Il n'existe pas d'unité asphalténique unique. Divers modèles ont été proposés dans la littérature pour décrire ces structures (asphaltènes de type continental, de type archipel). Cette polydispersité confère aux asphaltènes des propriétés fondamentales telles que l'auto-association et l'agrégation.
\end{abstract}

Face à cette complexité structurelle, la caractérisation des asphaltènes est loin d'être simple et se heurte à un choix limité de techniques analytiques. Des informations structurales moyennes sont obtenues, mais elles ne peuvent pas être représentatives de toute la variété chimique et structurale que peuvent contenir de telles matrices. L'état d'association des asphaltènes étant très sensible aux conditions opératoires (concentration, température, solvant), les résultats obtenus peuvent très fortement varier (de plusieurs ordres de grandeur) si les conditions expérimentales utilisées ne sont pas comparables. Les techniques faisant appel à des principes de mesure différents dans des conditions expérimentales différentes, les structures asphalténiques ne sont pas mesurées dans le même état d'agrégation.

On distingue deux types de caractérisation pour l'analyse des produits lourds : la caractérisation chimique et colloïdale. La caractérisation chimique permet de définir la composition chimique, les principales fonctionnalités et l'état structural des métaux et hétéroatomes présents dans les macromolécules. Les principales techniques analytiques qui peuvent être utilisées sont l'HPLC, la pyrolyse, la $\mathrm{RMN}{ }^{13} \mathrm{C}$, les techniques spectroscopiques (IR, XPS, EXAFS, XANES), etc. La caractérisation colloïdale est plutôt utilisée pour appréhender l'état de dispersion des entités asphalténiques dans un bon solvant ou dans leur milieu dit naturel que constitue le brut. Les paramètres caractérisant l'état colloïdal sont en particulier la masse moléculaire, la polydispersité en masse ou en taille et l'état d'agrégation faisant intervenir des agrégats de dimensions très variables. Différentes techniques peuvent être employées telles que la spectrométrie de masse, la diffusion des rayons $\mathrm{X}$ et neutrons aux petits angles (SAXS, SANS), la RMN ${ }^{1} \mathrm{H}$ à gradient de champ (coefficient de diffusion), ainsi que diverses techniques de fractionnement (ultracentrifugation, fractionnement par solvant, chromatographie d'exclusion stérique).

En amont de ces caractérisations, des étapes de fractionnement peuvent être réalisées afin de simplifier les matrices initiales trop complexes pour être caractérisées directement. 
Abstract - Physicochemical Characterization of Petroleum Fractions: the State of the Art High-boiling-point petroleum fractions $\left(350^{\circ} \mathrm{C}^{+}\right)$are known to be enriched in the most polar compounds such as resins and asphaltenes. Asphaltenes contain molecules of variable aromaticity with different contents of heteroatoms, metals and functional groups. An asphaltene fraction is a complex mixture of polydispersed molecules in terms of size and chemical composition. Such structures cannot be represented by only one model molecule. Several models have been proposed in the literature to describe these structures (continental and archipelago types). Due to this high polydispersity, specific properties such as aggregation are observed.

Detailed characterization of such highly complex products is difficult and the choice of analytical techniques that can be used is quite limited. Average structural information has been obtained, but it cannot be representative of all chemical and structural variety that such matrices may contain. The aggregation state of asphaltene macromolecules strongly depends on the experimental conditions (concentration, temperature and solvent). Significant variations in measurement may be induced if the operating conditions used are not similar. The techniques being based on different theories and being run in different experimental conditions are consequently not equivalent. The asphaltenic structures are not measured in the same aggregation state.

Heavy product characterizations can be divided into two types: the chemical and colloidal characterizations. The first one gives information on both chemical composition and main functional groups as well as the structural state of metals and heteroatoms in macromolecules. Numerous techniques are used such as high-performance liquid chromatography (HPLC), pyrolysis coupled with gas chromatography and mass spectrometry (PyGC-MS), ${ }^{13} \mathrm{C}$ nuclear magnetic resonance (NMR), and spectroscopic techniques (IR, $X P S, E X A F S$ and XANES). Colloidal characterization consists of the investigation of the dispersion of heavy fractions (asphaltenes and resins) as macromolecules in a good solvent or in their natural medium (maltenes). The main parameters that can define the colloidal structure are the molecular weight and the mass or size polydispersity of aggregates. Various techniques may be employed, such as mass spectrometry, scattering techniques (small-angle X-ray and neutron scattering), pulsed-field gradient nuclear magnetic resonance $\left(P F G^{-}{ }^{l} H N M R\right)$, as well as different separation methods (ultracentrifugation, solvent separation and size-exclusion chromatography).

As a preliminary step, fractionations have to be carried out in order to simplify these matrices, too complex to be directly characterized.

\section{INTRODUCTION}

The wide interest of heavy oil products has primarily appeared since the energy crisis of the 70's and 80's. For the most part, the availability of new oil reserves depends on the increase of the rate of oil recovery in the reservoir. Improved recovery methods encounter various physicochemical phenomena in which heavy products play a determining role (Haaland and Klovning, 1998). Refineries are more and more dependent on heavy crude feedstocks as sources of conventional crude oils decrease. Furthermore, the refining process is increasingly concerned with the conversion of atmospheric or vacuum residues as a consequence of the increase in demand for gasoline and middle distillates (Billon et al., 1994; Morel et al., 1997).

The main characteristics of heavy crudes (high viscosity and significant content of heteroatoms) are directly related to the major presence of compounds such as resins and asphaltenes which constitute the most polar fractions of these products. Their macrostructure is probably responsible for this high viscosity. The flocculation or the possible sedimentation of asphaltenes in these crudes can occur during reservoir exploitation, inducing pore plugging and permeability reduction (Leon et al., 2000; Rogel, 2000). Formation damage can appear near the well bore due to the formation of asphaltene deposits. Sedimentation of heavy fractions may occur during storage of these heavy products. Transportation is also concerned by the formation of large particles which are rich in asphaltenes, leading to fouling and plugging of facilities. During product blending, destabilisation of the product can be detected, producing sediments, whose concentration can be correlated to the presence of heavy fractions. Hydroconversion processes (Hyvahl, $\mathrm{H}$-Oil) require catalysts to remove accumulate metals (nickel and vanadium) and to desulphurise the feed. Large pore volume is necessary to store metal deposits and reduce the asphaltenic macromolecule diffusion through the pore structure before catalytic conversion. The deactivation of the catalyst due to coke deposit is strongly dependant on the heavy fractions concentration.

Although our knowledge has considerably improved in the last two decades, some industrial results are still not perfectly understood. In refining process, we know that feedstocks with very similar composition may convert in different ways or can induce variable aging of catalysts. 
The compositional analysis of heavy oil products has become a key step in various developments. However, the characterization of such species still remains a time consuming work despite all the efforts already made in this field. The complexity of these oil matrices tends to increase with their boiling point. A large variety of compounds is present in term of structures and number of molecules (Strausz and Lown, 2003).

Numerous studies carried out on heavy products analyses, were primarily related to asphaltenes and to a less extent, to resins. Two types of characterization can be distinguished. On the one hand, chemical characterization gives information on the chemical composition and function groups in macromolecules. Many studies of the structural state of heteroatoms in asphaltenes and resins have been published. The molecular characteristics of these species may vary from one crude to another. Within the same crude, results show that asphaltene molecules can be highly polydispersed. The main analytical tools used in chemical characterization are the liquid chromatography (SARA fractionation), elementary and oil analyses, nuclear magnetic resonance (NMR), infrared spectroscopy (IR), etc. From these analytical data, an average asphaltene molecule can be represented using complex tools of molecular modelling.

On the other hand, colloidal characterization may be interesting to observe the state of dispersion of the asphaltenic entities as macromolecules in a good solvent (usually aromatic) or in their own medium (crude). The required parameters are the molecular mass, the polydispersity in mass or in size and the state of aggregation with aggregates of varying sizes. Various techniques are employed such as X-ray and neutron scattering (SAXS and SANS), nuclear magnetic resonance (NMR) and rheology, as well as different techniques of fractionation (ultracentrifugation, fractionation by solvents, steric exclusion chromatography (SEC)).

The aim of this paper is to present a literature review of the main analytical techniques used for the heavy products characterization. Routine techniques as well as new conceptual ones are presented, the goal being to illustrate the feasibility and consider the coherence of the obtained results.

\section{HEAVY OIL FRACTIONS: DEFINITION AND COMPOSITION}

Heavy petroleum products correspond to the fractions that cannot be removed by the atmospheric distillation. They usually present a boiling point above $350^{\circ} \mathrm{C}$ with an API density lower than 20 .

\subsection{Physical Properties and Global Chemical Composition}

Heavy fractions, defined as molecules containing more than 25 carbon atoms $\left(\mathrm{C}_{25}\right)$, present a structural complexity which increases with the boiling point (Fig. 1) as well as the molecular weight, the density, the viscosity, the refractive index (aromaticity) and the polarity (contents of heteroatoms and metals).

These fractions are enriched in highly polar compounds such as resins and asphaltenes. They are composed of various

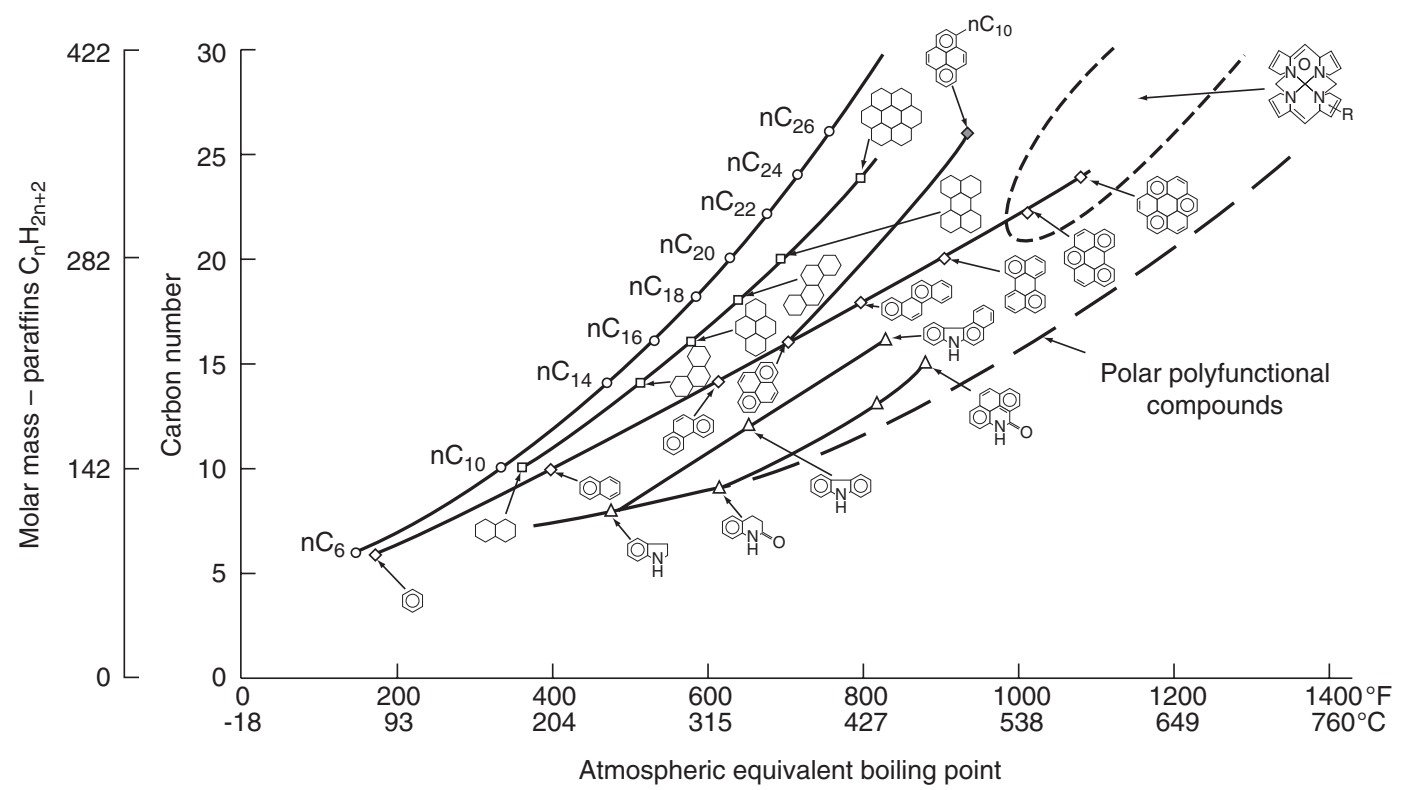

Figure 1

Evolution of molecular weights and structures as a function of the boiling point (from Altgelt and Boduszynski, 1994). 
TABLE 1

Elemental composition of two crude oils and their distillation cuts (AGO: Atmospheric gasoil; VGO: vacuum gasoil) (from Altgelt and Boduszynski, 1994)

\begin{tabular}{|c|c|c|c|c|c|c|c|}
\hline Crude oil & $\mathrm{C}(\%)$ & $\mathbf{H}(\%)$ & $\mathrm{S}(\%)$ & $\begin{array}{c}\mathbf{N} \\
(\mathbf{p p m})\end{array}$ & $\begin{array}{c}\text { Basic N } \\
(\mathbf{p p m})\end{array}$ & $\mathbf{H} / \mathbf{C}$ & $\mathrm{S} / \mathrm{C}$ \\
\hline \multicolumn{8}{|l|}{ Arabian Heavy } \\
\hline Whole crude & 84.5 & 12.5 & 2.8 & - & - & 1.78 & 0.012 \\
\hline Heavy naphtha $\left(150-204^{\circ} \mathrm{C}\right)$ & 84.5 & 14.4 & 0.11 & 0.3 & $<1$ & 2.04 & 0.0005 \\
\hline Kerosene $\left(204-260^{\circ} \mathrm{C}\right)$ & 84.4 & 14.1 & 0.46 & 1.0 & $<2$ & 2.00 & 0.002 \\
\hline $\operatorname{AGO}\left(260-350^{\circ} \mathrm{C}\right)$ & 84.4 & 13.1 & 1.5 & 30 & 15 & 1.86 & 0.007 \\
\hline $\operatorname{DSV}\left(350-540^{\circ} \mathrm{C}\right)$ & 84.6 & 12.2 & 3.1 & 940 & 208 & 1.73 & 0.014 \\
\hline $\operatorname{RSV}\left(550^{\circ} \mathrm{C}^{+}\right)$ & 83.5 & 10.9 & 5.5 & 4600 & 661 & 1.57 & 0.025 \\
\hline \multicolumn{8}{|l|}{ Alaskan North Slope } \\
\hline Whole crude & - & 12.3 & 1.47 & 1980 & - & 1.72 & - \\
\hline Heavy naphtha $\left(150-204^{\circ} \mathrm{C}\right)$ & 86.3 & 13.7 & 0.03 & 0.2 & - & 1.90 & 0.0001 \\
\hline Kerosene $\left(204-260^{\circ} \mathrm{C}\right)$ & 86.5 & 13.2 & 0.11 & 1.5 & 1 & 1.83 & 0.0005 \\
\hline $\operatorname{AGO}\left(260-350^{\circ} \mathrm{C}\right)$ & 86.0 & 12.8 & 0.55 & 88 & 40 & 1.79 & 0.002 \\
\hline $\operatorname{DSV}\left(350-540^{\circ} \mathrm{C}\right)$ & 85.6 & 11.7 & 1.45 & 2500 & - & 1.64 & 0.006 \\
\hline $\operatorname{RSV}\left(550^{\circ} \mathrm{C}^{+}\right)$ & 85.6 & 10.5 & 2.77 & 6800 & - & 1.47 & 0.012 \\
\hline
\end{tabular}

chemical species of different aromaticity, functional heteroatoms and metal contents (Murgich et al., 1996; Strausz et al., 2002), when compared to the crude or lighter fractions (Table 1).

\subsection{Structural Composition}

\subsubsection{Saturated and Aromatic Hydrocarbons}

Contrary to lighter fractions, in which the hydrocarbon structures are mainly aliphatic (paraffins with some mono and di-naphtenes) or monoaromatics, heavy fractions rather include naphtenic and aromatic structures with more than six alkylated cycles. Few olefins can be detected in the heavy fractions of straight run whereas they are more concentrated in coking or catalytic cracking fractions. The aromatic content increases with the boiling point, as well as the number of aromatic cycles in the structures. The aromatic distribution of vacuum gas oil (VGO, $\left.350-550^{\circ} \mathrm{C}\right)$ fractions is mostly centred on structures including from 1 to 3 polyaromatic cycles, whereas structures of residues $\left(550^{\circ} \mathrm{C}^{+}\right)$mainly contain polyaromatics of 5-6 cycles. Higher the boiling point is, more enriched in heteropolyaromatic structures the fractions are.

\subsubsection{Sulphur Compounds}

Sulphur compounds contained in residues are similar to sulphur species in lighter fractions, but in different proportions. They can be divided into five chemical classes: thiols, sulfides, disulfides, sulfoxides and thiophenes. The first four classes can be subdivided into cyclic and acyclic structures as well as in alkyls, aryls and alkylaryl derived species.
In addition, thiophenes are condensed polyaromatic structures with benzo-, dibenzo-, naphtobenzo-thiophenes and other derived structures.

In heavy fractions, major sulphur species are the thiophenics, followed by sulfide derivatives (cyclic and acyclic). Only small amounts of sulfoxide types are detected.

\subsubsection{Nitrogen Compounds}

Although nitrogen content in heavy crudes appears to be much lower than other heteroelements, it has a large influence in hydrotreatment processes as it induces catalyst poisoning. Two classes of nitrogen compounds are distinguished, the basic and the neutral ones with a ratio of basic compounds to neutral ones generally lower than unity.

The major basic nitrogen families characterized in $350^{\circ} \mathrm{C}^{+}$ fractions are quinolines structures containing from 2 to 4 aromatic cycles with different configurations (peri- or catacondensed with various alkylation degrees). Among them, the presence of benzo-, dibenzo-, tetrahydro-quinoleines and azapyrenes have been identified (Igniatiadis et al., 1985).

Concerning the neutral structures, a majority of carbazoles, benzo- and dibenzo-carbazoles families with different alkylation degrees were detected (Dorbon et al., 1982).

The repartition of the various neutral and basic families is strongly related to the geochemical type from which oil is issued. Differences result from relative abundance, alkylation degrees and isomer distributions (Merdrignac et al., 1998).

The presence of porphyrins structures is also detected in heavy oil fractions, depending on the organic matter type. Of extremely varied nature, they are generally complexed by nickel or vanadyl ion $(\mathrm{V}=\mathrm{O})$ (Goulon et al., 1984). 


\subsubsection{Oxygenated Compounds}

Oxygenated structures are also present in oil fractions but in low quantities. Mainly concentrated in the $350^{\circ} \mathrm{C}^{+}$fractions, different families have been identified such as phenolic compounds and carboxyl functions (carboxylic acids, esters, ketones, amides and sulfoxides) (Moschopedis and Speight, 1976).

\section{WHY CHARACTERIZATION OF HEAVY FRACTIONS IS LIMITED?}

The detailed structural characterization of heavy products is generally hard to achieve, mainly due to the great complexity of the fractions and the analytical technique limitations.

High boiling point fractions contain a significant number of isomers and organic compounds which can drastically increase with the cut point. These fractions present a broad range of polarities and can contain paraffinic, aromatic or heteroatomic molecules. Compounds of extreme polarities can present properties of nonmiscibility.

Due to such complexity, analysis of such fractions becomes tedious. Molecular analytical techniques, like gas chromatography generally used for lighter fractions can no longer be applied, or are generally not sufficiently resolutive. Averaged structural informations can still be obtained but are not representative of all the chemical and structural variety that such matrices can contain. Structural composition of high boiling point fractions, which can represent up to $20-45 \% \mathrm{w} / \mathrm{w}$ of the whole crude, still remains quite unknown today.

\section{FRACTIONATION METHODS}

To study and characterize these structures, a preliminary step of matrice simplification is recommended. The objective is to isolate subfractions of common characteristics, thereafter more easily analysable by various chromatographic, spectroscopic or other techniques.

Different fractionation methods can be considered. Separation as a function of the boiling point can be achieved by distillation. Separations by selective adsorption onto varied supports or through chemical derivations can be also proposed. Finally, the tolerance to solvents may be used to define solubility classes like for asphaltenes molecules (separation by polarity).

\subsection{Boiling Point Separation}

Results show a direct relationship between the boiling point and certain properties such as viscosity or density. However, boiling points are not directly proportional to the average molecular weight, but depend on the chemical structure of the compounds present in the fractions. It has been shown that polar compounds able to form aggregates are less volatile than the non-polar species of a similar given molecular weight. This can explain why polycondensed aromatic compounds enriched in heteroatoms (resins and asphaltenes) are mainly concentrated in high boiling point fractions.

Several normalized methods of distillation are proposed: preparative scale and simulated distillations (DS).

The True Boiling Point method (TBP, ASTM D2892) is a preparative distillation used to obtain distillation cuts from initial point to $400^{\circ} \mathrm{C}$ with $5^{\circ} \mathrm{C}$ cuts up to $170^{\circ} \mathrm{C}$ and $10^{\circ} \mathrm{C}$ cuts from $170^{\circ} \mathrm{C}$ to $400^{\circ} \mathrm{C}$. Potstill distillation (ASTM D5236) is often used to obtain vacuum distillation cuts $\left(400-550^{\circ} \mathrm{C}\right)$ with steps of $50^{\circ} \mathrm{C}$.

To control the quality of products or for routine analyses, simulated distillation (DS) is well adapted and can replace conventional distillation methods. Time can be saved and smaller sample volumes are required (few $\mathrm{mL}$ in simulated distillation versus 200 to $500 \mathrm{~mL}$ in preparative distillation). This technique is used at the analytical scale and normalized methods have been developed (ASTM D2887, D6352). The selectivity being higher, this technique can cover a wider temperature range than that of vacuum preparative distillations (Durand and Petroff, 1984). Simulated distillation is based on the hydrocarbons aptitude to be eluted according to their boiling point from a non-polar chromatographic column under specific conditions. Retention time (RT) of the species is converted into boiling point temperature by using a calibration curve, established from normal paraffin retention times. The normalized cumulative corrected sample areas of each consecutive recorded time interval are used to calculate the boiling range distribution. The boiling point temperature at each reported percent of increment is calculated from the RT calibration. A profile of cumulated percentages in function of the boiling point is obtained.

When applied to $550^{\circ} \mathrm{C}^{-}$distillation cuts, the conventional simulated distillation is generally used (ASTM D2887) (Feeney and Huber, 1984; Feillens et al., 1984). For the analysis of higher boiling point fractions $\left(550^{\circ} \mathrm{C}^{+}\right)$, high temperature $\left(430^{\circ} \mathrm{C}\right)$ gas chromatography allows to extend the carbon distribution up to $100\left(\mathrm{nC}_{100}-700^{\circ} \mathrm{C}\right)$ (ASTM D6352, Neer and Deo, 1995; Durand et al., 1998; Bacaud et al., 1998; Reddy et al., 1998). However, this technique has to face several limitations such as:

- the oven temperature below $430^{\circ} \mathrm{C}$ to avoid compound degradation;

- preliminary de-asphaltening required;

- extrapolation of calibration curve impossible due to modification of elution conditions.

On the other hand, these drawbacks are not encountered with supercritical fluid chromatography (SFC) (Schwartz, 1988; Shariff et al., 1994; M'Hamdi et al., 1997; Dahan et al., 2004). In this case, high temperatures are not needed 

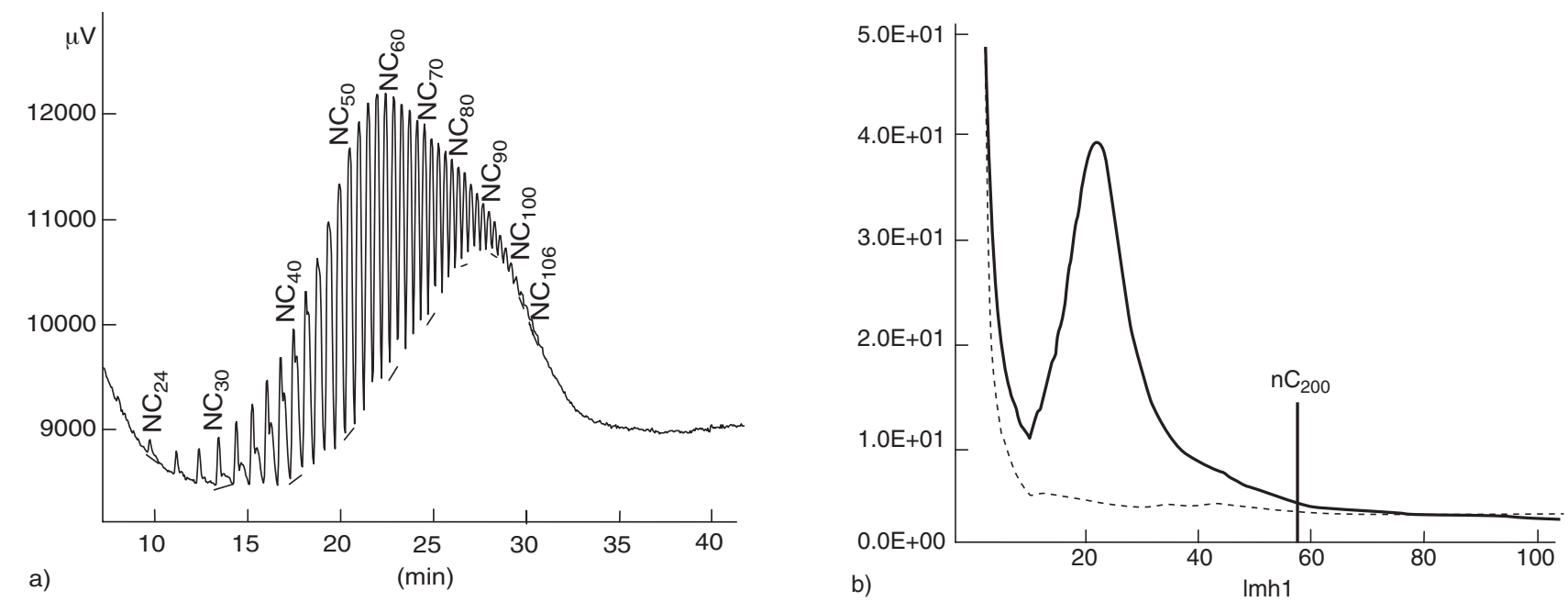

Figure 2

Supercritical fluid chromatogram of a: a) polywax P600/P1000 mixture and b) a Safanyia vacuum residue.

$\left(160^{\circ} \mathrm{C}\right)$ since the elution of the heavy products is governed by the sample solubility in the supercritical mobile phase $\left(\mathrm{CO}_{2}\right)$ and not by its volatility. Hydrogenated polyethylene wax mixture is used for the calibration of the SFC chromatogram (retention time as a function of the carbon number of the molecule) as shown in Figure 2a. Detection of $n-C_{120}$ $\left(750^{\circ} \mathrm{C}\right)$ compounds is easily obtained, but chromatograms (Figs. 2a, 2b) generally show that heavier products are still eluted above this retention time $\left(\mathrm{C}_{120}\right)$. A model of retention time versus the number of carbon atoms was carried out and allowed the elution up to molecules containing approximately 200 carbon atoms $\left(\mathrm{nC}_{200}\right)$ (Fig. 2b) (Bertoncini et al., 2005).

\subsection{Chemical Type Fractionation}

\subsubsection{De-asphaltening}

The precipitation of asphaltenes can be achieved by using several standard analytical procedures (ASTM D893, D2006, D2007, D3279). They mainly differ from each other in the experimental conditions. It has been shown that experimental yields but also asphaltene structure may vary considerably with the experimental scheme that has been used.

De-asphaltening is based on a sample flocculation in contact with a paraffinic solvent (antisolvent) under stirring during a given time and temperature. Parameters such as contact time, solvent/oil ratio, type of solvent, temperature and washing steps can strongly influence the precipitation (Speight, 1999).

Results show that the asphaltene yield tends to decrease when the carbon number of the antisolvent increases up to a value close to 9-10. The average molecular weight and the aromaticity ( $\mathrm{H} / \mathrm{C}$ ratio) increase with the carbon atom number of the paraffin used (Fig. 3a) (Ancheyta et al., 2002).
In the same way, structural changes and a decrease of the asphaltene yield are involved when the solvent/oil ratio decreases. Ratios above 30 (mL solvent/g of oil) are generally recommended in normalized methods where $\mathrm{n}$-heptane is used as flocculant (Fig. 3b).

The contact time parameter required for a complete precipitation is also very important. It has been shown that contact times of approximately 8 hours under reflux were necessary to obtain stable yields (Fig. 3c). To reach a good reproducibility, they must however range from 12 to 16 hours.

Finally, precipitation yields tend to decrease when filtration temperature and number of washing steps increase. Knowing that washing steps help to release compounds like resin type stayed encapsulated in asphaltenes, the evolution of the structural properties of remaining asphaltenes is in strong relationship with their aptitude to self aggregate. Consequently, the density and the average molecular weight of such species increase, whereas their solubility in the medium decreases (Alboudwarej et al., 2002).

\subsubsection{SAR Separation}

From a de-asphalted cut, SAR separation is used to obtain saturated, aromatic and resins (or polar) fractions eluted by polarity. The techniques generally used are the preparative liquid chromatography (flash chromatography), analytical chromatography (HPLC) or thin layer chromatography (TLC). This type of separation is usually adapted for the $300^{\circ} \mathrm{C}^{+}$cuts, as lighter products might be lost during purification steps.

The main advantage of the flash chromatography is the possibility to recover fractions in large quantities, which can be further characterized by various analytical techniques. Products are adsorbed on a chromatographic support and are 

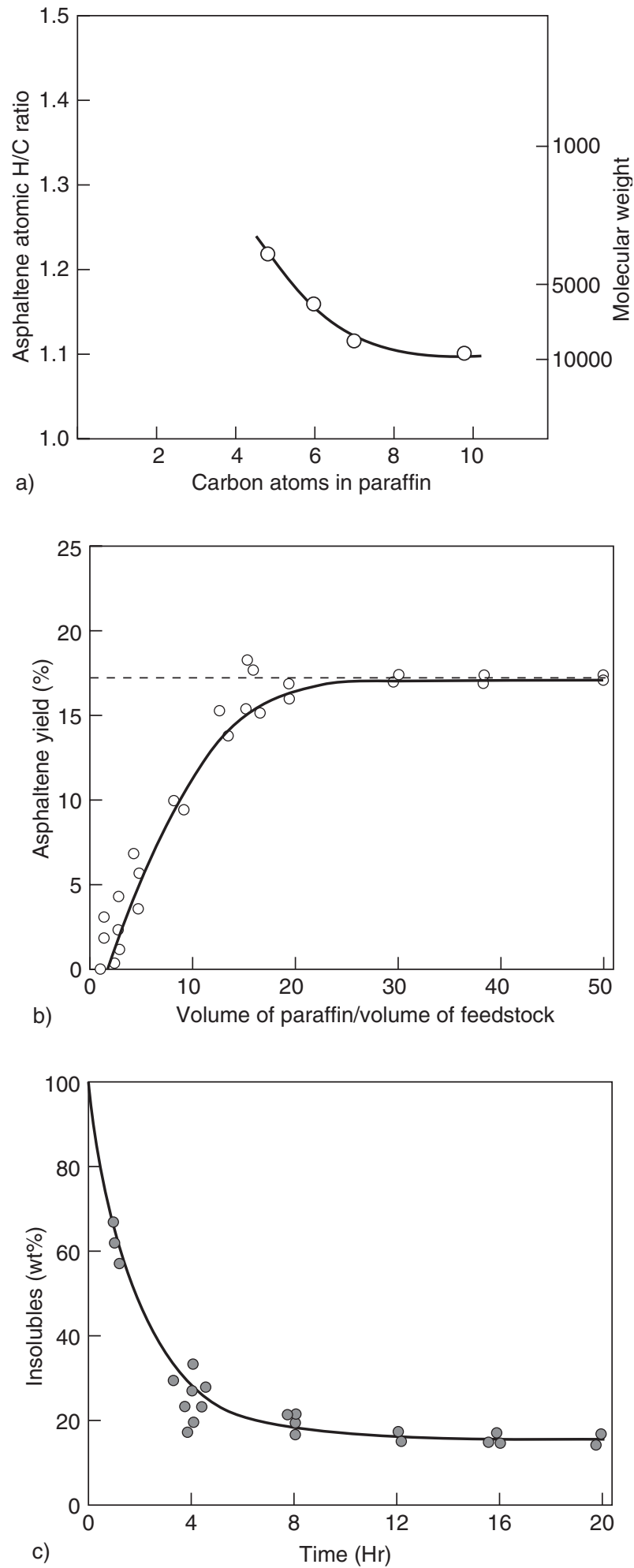

Figure 3

a) Evolution of the asphaltene aromaticity and the average molecular weight as a function of the number of carbon atoms of the paraffinic antisolvent used for asphaltene precipitation. Evolution of the asphaltene yield as a function of b) solvent to oil ratio; c) contact time with reflux (solvent to oil ratio 30/1) (from Speight, 1999). eluted by polarity. Mass balances are obtained by weighing collected fractions. Drawbacks of this technique are time consuming (6-14 h) and use of large solvent quantities (liter scale). Many methods have been developed, and largely routinely applied in refineries and laboratories. Round robin tests showed that results could strongly vary according to methodologies (solvents, active phases). Few normalized ASTM methods have been developed in this field such as ASTM D2007 (Peramanu and Pruden, 1999) or ASTM D4124 which has been derived from the Corbett method. Method standardization is a real need especially when results of different studies have to be compared.

As an alternative method, TLC is faster and more economic than the flash chromatography. Being non-preparative, this technique is used to separate complex mixtures by silica support adsorption (plates or rods) (Cebolla et al., 2003). The equipment is partly or fully automated, except the support which is single use. Products are deposited at the bottom of the support and eluted according to solvents chosen by decreasing polarity (Barman, 1996). Detection is carried out by direct sweeping of the support without complete elution of the fractions (Sharma et al., 1999). Detection modes usually used are the densitometry (UV/fluorimétrie) (Cossio et al., 2000; Matt et al., 2003) or the FID (Sharma et al., 1998). When compared to the flash chromatography, results show that these techniques are not equivalent, the principle and detection modes being different.

SARA fractionation may be also predicted through models. Correlations have been proposed to predict molar volumes as well as some other properties (Akbarzadeh et al., 2002). These empirical equations can however involve large uncertainties when extrapolated beyond the study field (Kodal and Sayeh, 1990; Mannistu et al., 1997). As an alternative, molar volumes may be estimated with cubic equation of state (Peng and Robinson, 1976). Unfortunately, they generally do not provide accurate predictions.

SARA fractions can be also predicted from Infrared (IR) or Near Infrared (PIR) spectra (Aske et al., 2001). Compared to chromatography, the main advantages of such spectroscopic techniques are simplicity and time saving. However, developing robust models adapted to a broad range of samples can be very long (Satya, 2004).

\subsubsection{ABAN Fractionation}

Applied to whole heavy cuts (preliminary de-asphaltening not required), this method is used to separate samples in acid, basic, amphoteric and neutral fractions (ABAN). The neutrals are then separated into saturates and aromatics. Several methods were developed (Green et al., 1984), then improved (Kim and Branthaver, 1996; Al-Zaid et al., 1998), but still remain rather long and laborious. A scheme of the fractionation is described in Figure 4 (Mc Kay et al., 1981). 
This type of separation, dependent on the supports used, is primarily based on compound reactivities and their strong capacity to form hydrogen bonds (acid and basic fractions) or complexes by charge transfer ( $\pi$-donor) (amphoteric fraction). Consequently, these three fractions are mainly concentrated in heteroatomic polar compounds able to form aggregates through hydrogen bond interactions. The acid fraction may contain phenols, pyrroles and species with carbonyl groups. Nitrogen compounds like azaarenes and amides are identified in the basic fraction. Species contained in the amphoteric fraction are especially polycondensed aromatic compounds enriched in heteroatoms.

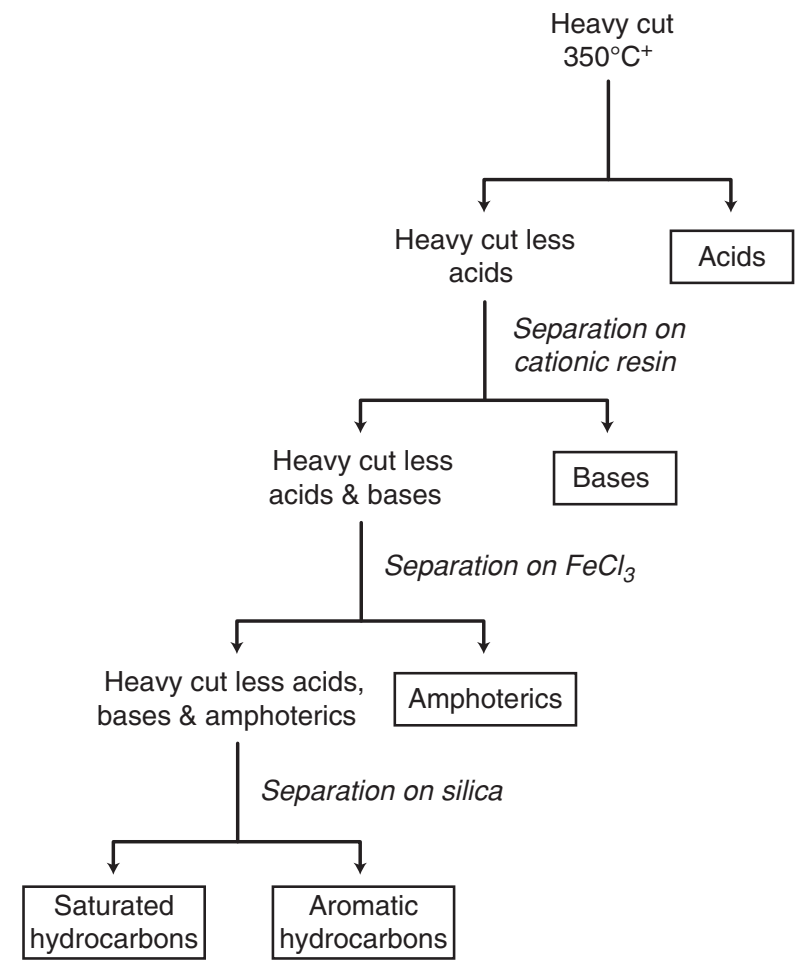

Figure 4

ABAN (acid, basic, amphoteric, neutral) separation scheme of a high boiling point fraction $\left(350^{\circ} \mathrm{C}^{+}\right)$.

This separation scheme may reduce molecular aggregation of polar compounds by fractionating them. In this way, we may have access to another degree of detail (Hammami et al., 1998). Back to the asphaltene concept, these structures will form aggregates of polar and polarisable compounds due to intermolecular associations. The composition of such aggregates is governed by the solubility of structures during the separation. Asphaltene compounds is distributed in acid and basic fractions of heavy cuts.

\subsection{Solubility Fractionation}

A solubility fractionation can be used to study the correlation between solubility and molecular structure of subfractions that have been obtained. This protocol is based on the asphaltenes $\left(\mathbf{C}_{7}\right)$ reprecipitation in toluene by various antisolvents of different polarities (normal light paraffins, acetone, methanol). Comparisons between subfractions highlight the high chemical polydispersity of asphaltenes (Szewczyk et al., 1996). Based on the molecular characterization of the subfractions as well as the nature of the studied medium (toluene/anti-solvent ratio), mechanisms of precipitation can be suggested (Buenrostro-Gonzales et al., 2002). Results showed that the solubility of asphaltenes was mainly related to either the aromaticity and aliphaticity factors or polarity of asphaltenes (Andersen, 1997; Andersen et al., 1997; Sharma et al., 2000a, b; Andersen et al., 2001a; Neves et al., 2001; Wattana et al., 2002).

\subsection{Others}

Other types of fractionation, that will not be described in detail here, can be also used, such as chemical derivations with acetylation of oxygenated compounds studies (Green and Reynolds, 1989), acid-base fractionations (Moschopedis et al., 1976; Mc Kay et al., 1976, Merdrignac, 1997), sulfide oxidations (Payant et al., 1989). Selective complexations (Nishioka and Tomich, 1993; Altgelt and Boduszynski, 1994; Strausz and Lown, 2003), selective degradations (RICO - Ruthenium Ion Catalysed Oxidation) (Boukir et al., 1998; Su et al., 1998; Strausz et al., 1999a, b), and supercritical fluid extraction (Singh et al., 1992; Shi et al., 1997) are also interesting methods.

\section{CHEMICAL CHARACTERIZATION}

Once the matrix simplified, information on the chemical composition and the main functional groups contained in heavy oil fractions can be obtained by using chemical characterization techniques. The most commonly used methods are described below. Other techniques may be applied, but are generally developed for specific studies.

\subsection{Py/GC-MS}

Pyrolysis/Gas chromatography/Mass spectrometry coupling (Py/GCMS) is known to be a qualitative or semi-quantitative technique according to the selected calibration used. Information on the general composition of asphaltenes (Nali et al., 1994), hydrocracked products (Srinivasan, 1995) and residues (Erhmann and Izquierdo, 1994) can be obtained. Pyrolysis products are directly analysed by GC/MS and/or FID (field ionisation detector). The main drawback of this 
technique is the difficulty to connect the pyrolysate fragments to the original structure of the compounds. Results showed, for instance, that thermal maturity would be inversely proportional to the molecular mass of pyrolysates and original asphaltenes (Wilhems et al., 1993). This would confirm that asphaltenes are made of a polydisperse complex mixture of naphtenic and polyaromatic molecules bounded with aliphatic bridges and substituted by short aliphatic chains (Calemma et al., 1998; Artok et al., 1999).

\subsection{HPLC}

The use of HPLC (high performance liquid chromatography), with which most of the detectors can be coupled (ultraviolet (UV), fluorescence, IR (infrared), refractometer, MS (mass spectrometer)) is interesting to analyse polyaromatic hydrocarbons (HAP) of heavy products. However, for the most part it has to be used in a normal phase because of the compound solubility and compatibility with solvents (organic). Derived supports (amino-, cyano- or diol-silica) are classically used generally coupled with UV detector. The selected wavelengths are usually lower than $300 \mathrm{~nm}$ for one to three aromatic cycles containing products and higher in case of four to seven aromatic cycle compounds (Hatrik and Lehotay, 1994; Yan et al., 1996). However, it has been shown that an eight polycondensed aromatic structure, produced during catalytic hydrotreatment, has been isolated in reverse phase HPLC (Fetzer and Kershaw, 1995; Simoneit and Fetzer, 1996).

\section{3 ${ }^{13} \mathrm{C}$ and ${ }^{1} \mathrm{H}$ NMR: Structural Motives}

Both techniques were used to obtain structural information on samples (Brown et al., 1960; Clutter et al., 1972). Illustrations of proton and carbon NMR spectra are presented respectively in Figures 5a and 5b. Three types of protons can be distinguished:

- aromatic protons (Haro),

- protons located in $\alpha$ of an aromatic cycle $(\mathrm{H} \alpha)$,

- protons located in $\beta$ and $\gamma$ of an aromatic cycle $(\mathrm{H} \beta$ and $\mathrm{H} \gamma)$.

With ${ }^{13} \mathrm{C}$ NMR, two major carbon types like aromatic and aliphatic may be distinguished (Fig. 5b). Nevertheless, from this spectrum, little information like the aromaticity factor can only be obtained (ratio between the number of aromatic and total carbons) as well as the quantitation of aromatic and aliphatic carbons. To extract more data, spectral edition has to be used, which consists in varying the time between two pulses $(\tau)$ for both aliphatic and aromatic carbons. Then, from linear spectral combinations, several structural parameters can be calculated:

- quantification of aliphatic carbons: $C_{\text {quat }}$ (quaternary carbons), $\mathrm{CH}, \mathrm{CH}_{2}$ and $\mathrm{CH}_{3}$;

- quantification of aromatic carbons: $C_{\text {aro-total }}, C_{\text {quat }}$ (quaternary condensed + substituted carbons $\left(C_{\text {quat }}=C_{\text {quat-cond }}+\right.$ $\left.C_{\text {quat-sub }}\right)$ ) and $C_{\text {aro }}-\mathrm{H}$ (see Fig. 5c);

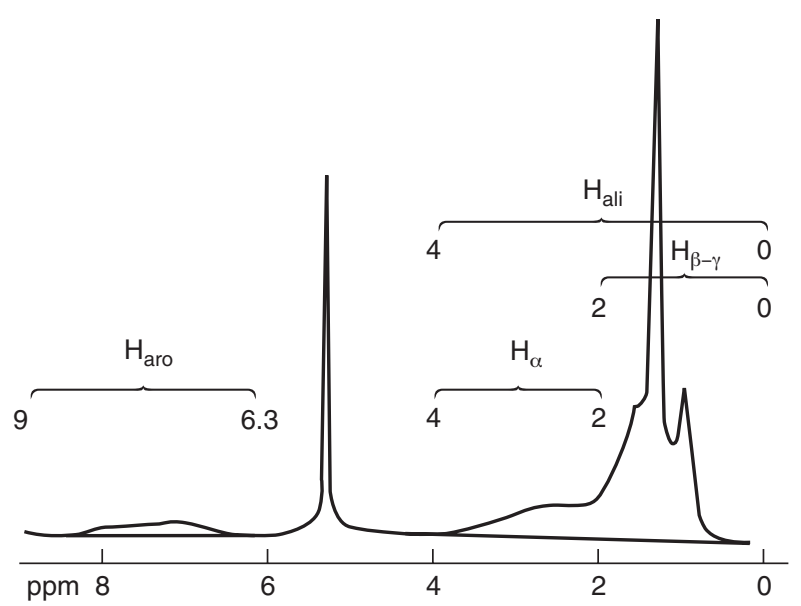

a)

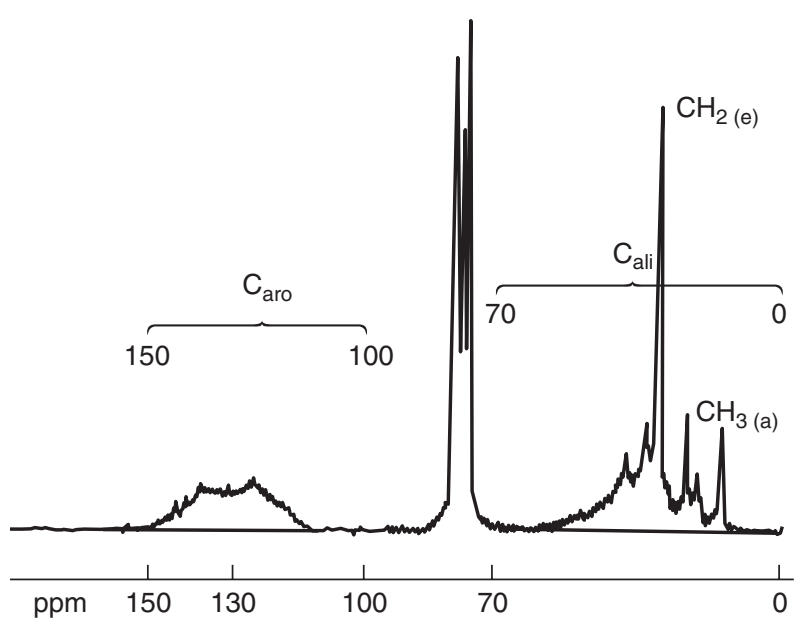

b)

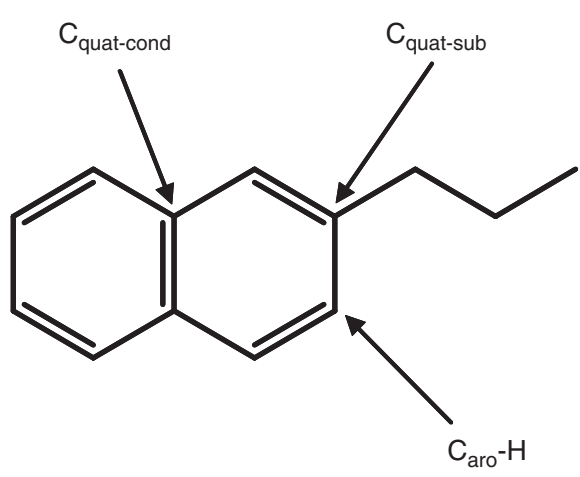

c)

Figure 5

a) ${ }^{1} \mathrm{H}$ and b) ${ }^{13} \mathrm{C}$ NMR spectra obtained for an asphaltenic fraction. c) Illustration of different type of aromatic carbons. 
- $\mathrm{C} / \mathrm{H}$ aliphatic and $\mathrm{C} / \mathrm{H}$ aromatic ratios;

- substitution index (SI) $=\frac{C_{\text {quat-sub }}}{C_{\text {aro-total }}-C_{\text {quat }- \text { cond }}}$;

- condensation index $(\mathrm{CI})=\frac{C_{\text {aro-total }}-C_{\text {quat }- \text { cond }}}{C_{\text {aro-total }}}$.

Such parameters are used to determine the structure of the studied fractions taking into account the aliphatic, aromatic, alkylated or polycondensed aromatic characters, the number of aromatic cycles as well as the alkyl chains length. This type of information is particularly useful in hydroconversion and hydrocracking where the product structures and coke formation may be predicted.

Several applications have been published, such as the structural study of residues (Favre, 1984; Hamid, 2000) or asphaltenes (Masuda et al., 1996; Sharma et al., 2000a, b). Results show that asphaltene molecules (from Koweit crudes) may consist of a number of polycondensed aromatic units (comprised between 5 and 9) linked together by alkyl chain bridges with or without heteroatoms (Ibrahim et al., 2003). Asphaltenes from different geochemical origins and of various aromaticities seem to present similar CI and SI with a number of condensed aromatic cycles close to 7 (Calemma et al., 1995).

\subsection{Fourier Transform Infrared Spectroscopy (FTIR)}

In combination with other techniques, this quantitative technique (Beer Lambert equation) is used to obtain detailed information on functional group distributions of heavy products $\left(\mathrm{CH}_{\mathrm{n}}, \mathrm{OH}, \mathrm{NH}\right.$ and various $\mathrm{CO}$ functions) (Lin-Vien

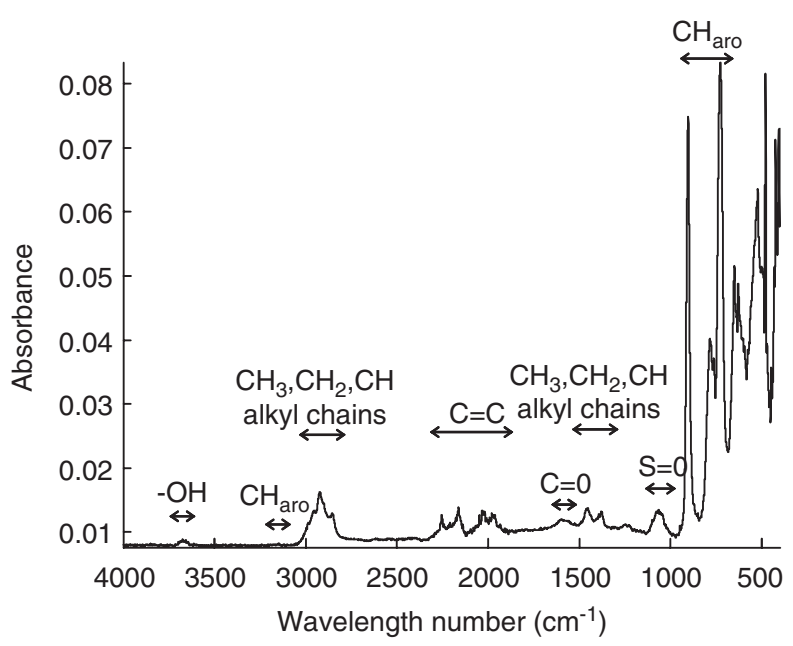

Figure 6

Fourier transform infrared spectrum of an asphaltenic fraction et al., 1991; Algelt and Boduszynski, 1994). A FTIR asphaltene spectrum is illustrated in Figure 6. Heavy products can be characterized in terms of oxidation, aromaticity, aliphaticity, ramification, length of alkyl chains and substitution (Boukir et al., 1998). Various examples were studied: characterization of residues, resins and asphaltenes fractions of different polarities (Nalwaya et al., 1999; Buenrostro-Gonzales, 2001).

The choice of the solvent used for the experiments is important since the aggregation state of the molecules might be minimized or maximized. The quantitation of groups absorbing in very close areas can then be more precise (Mc Kay et al., 1976). Calibration curves have been established for each type of groups and response factors have been determined (Green et al., 1985).

\subsection{XPS (X-Ray Photo-Electron Spectroscopy) EXAFS (Extended X-Ray Fine Structure) XANES (X-Ray Absorption Near Edge Spectroscopy)}

XPS, EXAFS and XANES techniques are used to obtain information on the environment and chemical functionalities of the sulphur, nitrogen and metal elements.

Data on the electronic structure of the probed chemical element ( $\mathrm{S}$ or $\mathrm{N})$ are measured by XANES analysis. This gives information about the oxidation degree of the studied element or on the presence of functional groups that can modify its electronic structure (electro-attractor, electrodonor groups). EXAFS analysis is more dedicated to the measure of the local atomic structure in the very close vicinity of the probed element in term of interatomic distances, nature and number of neighbours. XPS is a global analysis giving access to the oxidation degree as well as the functionalization of the elements.

Studies described in the literature showed that XANES ( $\mathrm{K}$ and LIII edges), when applied to asphaltenes, is suitable to differentiate various chemical forms from sulphur such as thiophenes, sulfides (alkyls and di-sulfides) and oxidized species (sulfoxide, sulfone, sulfonate and sulfate) (Sarret $e t$ al., 1999; Gorbaty et al., 2001). The same work has been done on nitrogen compounds where pyridinic and pyrrolic structures have been differenciated (Mitra-Kirtley et al., 1993). Nickel and vanadium compounds have been also extensively investigated by EXAFS and XANES techniques (Goulon et al., 1984) at the same extent than the size exclusion and reverse-phase chromatography (Biggs et al., 1985a, b; Fish et al., 1984). The major part of metallic atoms is present in petro-porphyrin species, but the structure of nonporphyrinic fractions still remains rather unknown.

As a conclusion to this section devoted to chemical characterization, we can highlight that all this chemical information deduced from various analytical techniques may be used to propose structural models of average molecules (resins or asphaltenes) (Bunger and Li, 1981; Strausz et al., 
a)

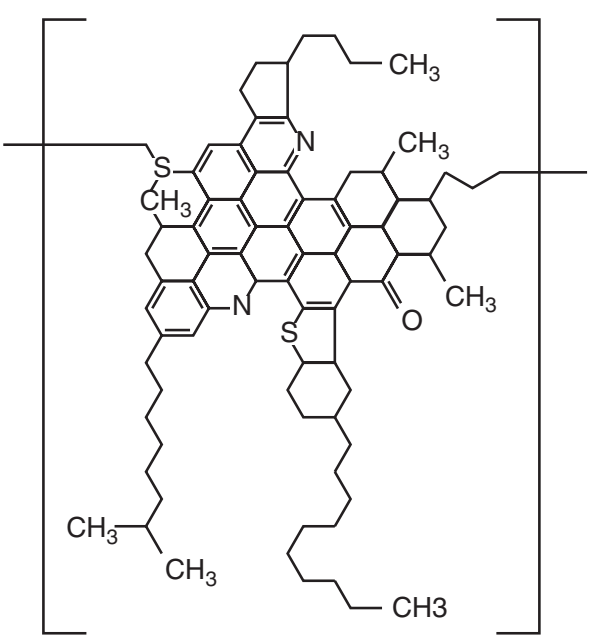

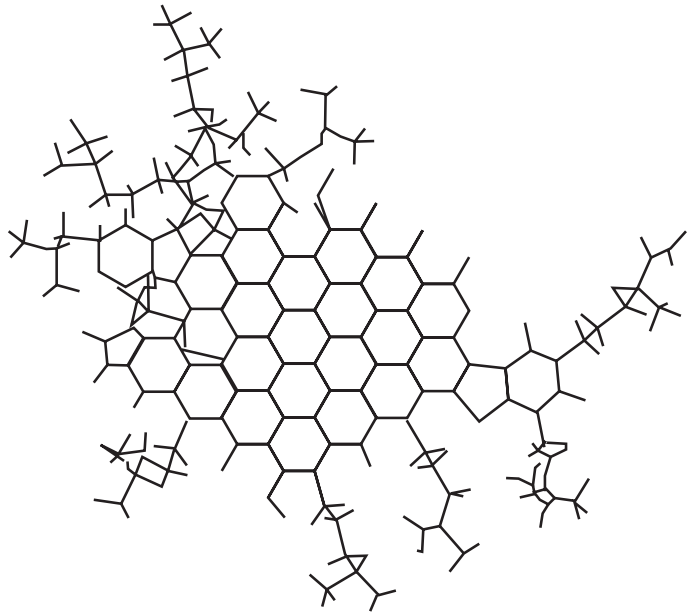

c)

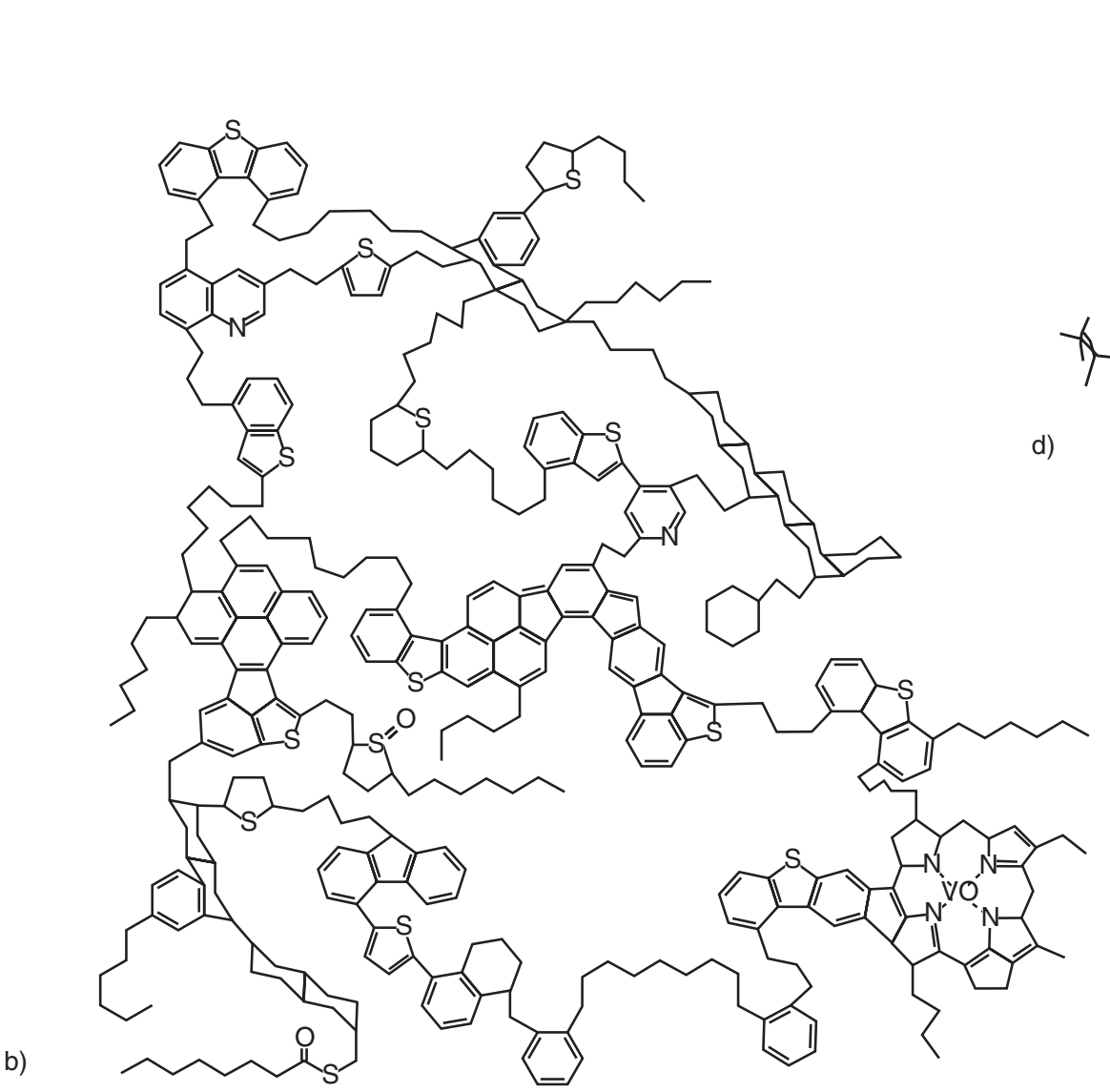

Figure 7

Representation of different asphaltene models: a) from venezuelian crude oil (Bunger and Li, 1981); b) Athabasca asphaltene (Strausz et al., 1992); c) the continental type and d) the archipelago type (from Murgich, 2003). 
1992) (see Fig. 7a, b). Softwares giving three dimensional representations have been developed (Kiet et al., 1978; Oka et al., 1977; Kowalewski et al., 1996; Murgich, 2003). It is recognized that such structures cannot be represented by only one model molecule. Some authors showed that a minimum of six model molecules was necessary for a molecular representation of asphaltenes (Mc Caffrey et al., 2003). From all studies, asphaltenes seem to be described through two average models:

- the continental type, in which asphaltenes are represented as large central aromatic region (Fig. 7c),

- the "archipelago" type, where asphaltenes are made of smaller aromatic regions linked by bridging alkanes (Fig. 7d) (Yen et al., 1961; Murgich et al., 1996; Yen, 1998; Andersen et al., 2001b; Yarranton et al., 2002; Murgich, 2003 and literature cited therein).

\section{COLLOIDAL CHARACTERIZATION}

In complement to the chemical investigation, the colloidal characterization is used to study the entities dispersion of heavy fractions, such as asphaltenes for example, as macromolecules in a good solvent or in their natural medium (crude). One of the colloidal parameters generally required is the average molecular weight. As shown by some authors (Tissot, 1981; Speight et al., 1985), significant variations in the molecular weight measurement are observed in the literature depending on the technique which has been used (Table 2). Several reasons can explain these results:

- Asphaltene polydispersity; asphaltenes form a heterogeneous mixture of highly polydispersed molecules in terms of size and chemical composition (Szewczyk et al., 1996; Groenzin and Mullins, 2000; Sheu, 2002). For polydispersed systems, several average molecular weights can be defined:

$$
\begin{aligned}
& M_{n}=\frac{\sum N_{i} M_{i}}{\sum N_{i}}, \quad M_{w}=\frac{\sum N_{i} M_{i}^{2}}{\sum N_{i} M_{i}}, \\
& M_{z}=\frac{\sum N_{i} M_{i}^{3}}{\sum N_{i} M_{i}^{2}}, \quad M_{z+n}=\frac{\sum N_{i} M_{i}^{3+n}}{\sum N_{i} M_{i}^{2+n}}
\end{aligned}
$$

with:

$N_{i}$ : number of molecules of $M_{i}$ molecular weight;

$M_{i}$ : molecular weight in $\mathrm{g} / \mathrm{mol}$;

$M_{n}$ and $M_{w}$ are respectively the number average molecular weight and the weight average molecular weight;

$M_{z}$ and $M_{z+n}$ are average molecular weight of higher orders.
TABLE 2

Examples of average molecular weights of asphaltenes from several

\begin{tabular}{|c|c|}
\hline Technique & Molecular weight $(\mathrm{g} / \mathrm{mol})$ \\
\hline Ultracentrifugation & 300000 \\
\hline Osmotic pressure & 80000 \\
\hline Ultrafiltration & $80000-140000$ \\
\hline Boiling point elevation & $2500-4000$ \\
\hline Freezing point depression & $600-6000$ \\
\hline Vapor pressure osmometry & $1000-8000$ \\
\hline Viscosity & $900-50000$ \\
\hline Light scattering & $1000-4000$ \\
\hline
\end{tabular}
crudes measured by various techniques (from Speight et al., 1985)

- Molecular associations: in solution, these asphaltenic entities may associate to form aggregates. Operating conditions, such as asphaltene concentration, temperature and solvent mainly influence this aggregate formation. For very low concentrations, a more or less complete dissociation of the aggregates, giving rise to elementary asphaltene molecules, was suggested. Some authors compared this behaviour to micelle formations above a certain critical micellar concentration (CMC) as known for surfactant molecules in solution (Andersen and Birdi, 1991; Sheu et al., 1991; Sheu et al., 1992; Evans and Wennerström, 1998). However, this micellization concept has been the subject of some controversy. Based on calorimetric titrations, other co-workers showed that the self-association of asphaltenes may occur step-wise, independently from a CMC (Murgich et al., 2002; Merino-Garcia and Andersen, 2003, 2004a, b). There is no formation of micelle, but formation of molecule aggregate of colloidal size. In the continental configuration (see Fig. 7c), the individual aromatic layers can stack (by four or five) to form elementary particles. If this stacking was observed for asphaltenes in the solid state, no experimental evidence was carried out in solution in good solvent. The interactions involved in such molecular associations are $\pi-\pi$ interactions between polycondensed aromatic structures and hydrogen bounds (Brandt et al., 1995). The estimated molecular weight of such particles may reach $10000 \mathrm{~g} / \mathrm{mol}$ with a radius of gyration $(R g)$ of $20 \AA$. Finally, these particles may self-associate to form colloidal aggregates. They are of various sizes and their molecular weights can range from $10^{4}$ to $10^{5} \mathrm{~g} / \mathrm{mol}$ $(R g=43$ Å) (Ravey et al., 1988; Fenistein, 1998; Fenistein et al., 1998; Coustet, 2003 and literature cited therein). In the archipelago type, interactions that are involved in the association mechanisms are similar to those described for the continental type: stacking and hydrogen bonds. However, several rotations of bridging chains are needed to reach the optimum conformation 
allowing the $\pi-\pi$ interactions. With this type of structure, intramolecular associations are then possible. The aggregate formation is consequently more complex with this archipelago model since there is a combination between stacking, bridged interactions and hydrogen bonds (Murgich, 2005).

Different techniques are used for macrostructural investigation of asphaltenes in solution, such as vapour pressure osmometry (VPO), size exclusion chromatography (SEC), mass spectrometry, Small Angle X-ray and Neutron Scattering (SAXS and SANS) and the NMR.

The techniques being based on different theories and being run in different experimental conditions, colloidal aggregates formed by asphaltenes are different in each case. The asphaltenic structures are not measured in the same state (Speight et al., 1985). Yen model (Yen et al.,1961; Yen, 1988) can give an illustration of this aggregation process (Fig. 8). We can draw the scope of molecular weight measurements of some techniques, which will be presented later, as a function of the association state of asphaltenes. The reported MW are either those of aggregate molecules, or dissociated species. In this way, terms of apparent masses are more appropriate, which only represent an average MW of the measured mixture.

\subsection{Vapour Pressure Osmometry (VPO)}

This technique consists in measuring the thermoelectric effect of the vapour tension decrease of a solution compared to a pure solvent. An average molecular mass in number is measured $\left(M_{n}\right)$. The $M_{n}$ measurement is strongly influenced by the association state of asphaltenes depending on the solvent polarity, the asphaltenic concentration and temperature of measurement. As shown in Table 3, an increase of the temperature induces a dissociation of the aggregates which leads to a decrease of the molecular weight. In the same way, molecular masses tend to decrease with the dissociating solvent power. As an illustration, the $M_{n}$ of asphaltenes from Alberta crudes range between 2400 and $4200 \mathrm{~g} / \mathrm{mol}$ in pyridine at $T=37^{\circ} \mathrm{C}$, whereas in less dissociating solvents, higher masses of 4000 to $6700 \mathrm{~g} / \mathrm{mol}$ are measured. In such apolar solvents, asphaltenes tend to strongly associate and the presence of aggregates is detected whatever the concentration.

Other thermodynamic techniques (not detailed here) can be used such as ebulliometry and cryoscopy.

\subsection{Size Exclusion Chromatography (SEC)}

The size exclusion chromatography is used to separate molecules according to their hydrodynamic volume. The
Asphaltene molecules

$\mathrm{MW}=500-1000 \mathrm{~g} / \mathrm{mol}$
Elemental particule $\mathrm{MW}=10000 \mathrm{~g} / \mathrm{mol} \mathrm{Rg}=20 \AA$

\author{
Agregrates \\ $\mathrm{MW}=10^{4}-10^{5} \mathrm{~g} / \mathrm{mol} \mathrm{Rg}=43 \AA$
}

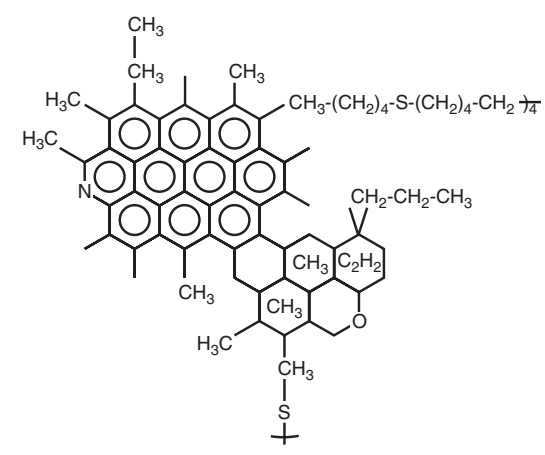

MS

Molecular scale

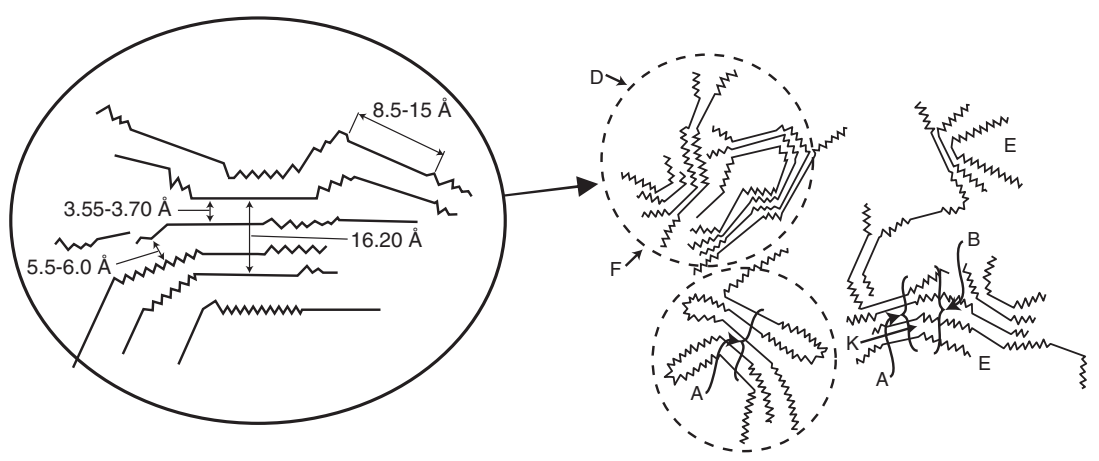

SEC $\square$ VPO
SAXS

Macroscopic scale

Figure 8

Domain of MW measurements of some analytical techniques as a function of the aggregation state of asphaltenes (use of the continental type model). 
TABLE 3

Influence of experimental conditions on asphaltene MW obtained by VPO (from Speight et al, 1985)

\begin{tabular}{l|c|c|c|c}
\hline \multirow{2}{*}{ Asphaltenes (Alberta) } & \multicolumn{4}{|c}{$\bar{M}_{n}$} \\
\cline { 2 - 5 } & Benzene $37^{\circ} \mathrm{C}$ & Pyridine $37^{\circ} \mathrm{C}$ & Nitrobenzene $100^{\circ} \mathrm{C}$ & Nitrobenzene $130^{\circ} \mathrm{C}$ \\
\hline Lloydminster & 6670 & 4220 & 2470 & 1920 \\
Sparky & 5885 & 2440 & 1700 & 1650 \\
Mannville-3 & 4905 & 2550 & 1790 & 1630 \\
Athabasca & 4850 & 2655 & 1890 & 1825 \\
Mannville-1 & 3975 & 2400 & 1860 & 1660 \\
\hline
\end{tabular}

supports are made of gels of controlled porosity. The system is calibrated by using monodisperse polystyrene polymers. SEC data enables to describe mass distributions (in polystyrene equivalent) according to weight averages previously defined.

The main limitation of this technique is the combination of:

- the tendency of asphaltenes to adsorb on the support, leading to an underestimation of the molecular weight;

- the aggregation of asphaltenes depending on the operating conditions, leading to an overestimation of the molecular weight (Brulé, 1980; Ducouret, 1987; Domin et al., 1999; Merdrignac et al., 2004a; Ascanius et al., 2004).

Routinely used, SEC is a useful technique when applied to the heavy products characterization, even though masses are not absolute. Many applications have been described in the literature (Sharma et al., 2000b). For instance, SEC has been used to study aggregation phenomena (Rietjens and Nieuwpoort, 2001) and type of interactions involved (hydrogen bonds) (Monin and Vignat, 1984). Asphaltenes of different organic matter type can be differentiated (Merdrignac et $a l .$, 2004a). SEC is also a useful tool to follow up the hydroconversion of various feeds (Kodera et al., 2000; Bartholdy et al., 2001; Guibard et al., 2004). Figure 9 illustrates the evolution of the asphaltene aggregates mass distributions observed during hydrotreatment performed at different severities. For the feed, the two large peaks may be attributed to high mass aggregates ( $\mathrm{MW} \approx 10000 \mathrm{~g} / \mathrm{mol}$ in eq. PS) and lower mass aggregates (MW $\approx 3000 \mathrm{~g} / \mathrm{mol}$ in eq. PS). At $50 \%$ of asphaltene conversion, results show a decrease of high molecular mass aggregates and an increase of the proportion low to high molecular weight peaks. This tendency is confirmed and strongly increased for the effluent converted at $70 \%$.

\subsection{Mass Spectrometry}

The potential of this technique is the multiple variety of sources and analysers that can be coupled. Applied to heavy products and specifically to asphaltenes, the choice is however limited due to the polydispersity, the aggregation and the low volatility of such samples. Important analytical questions arise like the ionization yield, the possibility of multiple charge formation, the presence or not of fragmentation.

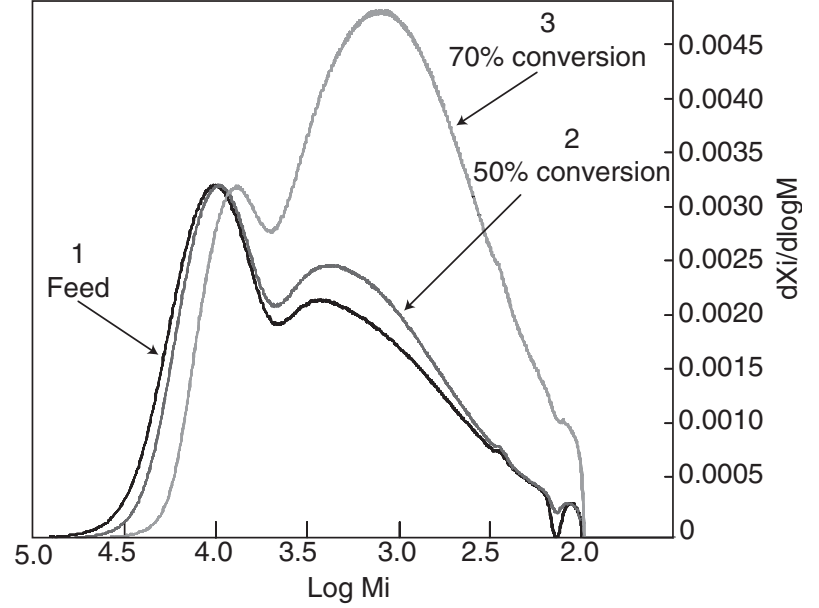

Figure 9

SEC chromatograms of asphaltenes from (1) a feed and effluents converted at (2) $50 \%$ and (3) $70 \%$. Conditions: tetrahydrofuran, PS-DVB columns, $\mathrm{C}=5 \mathrm{~g} / \mathrm{L}$, flow rate $=1 \mathrm{~mL} / \mathrm{min}$, $\mathrm{T}=40^{\circ} \mathrm{C}$ (from Merdrignac et al., 2004a).

Based on these points, three systems that are the most adapted to heavy petroleum fractions have been used (Dutta and Harayama, 2001; Cunico et al., 2002; Tanaka et al., 2002; Robins and Limbach, 2003):

- Matrix Laser desorption ionisation/time of flight (MALDI-TOF): adapted for polar and aromatic compounds.

- Atmospheric pressure chemical ionisation/quadripole/ time of flight mass spectrometry (APCI-Q-TOF): adapted for weakly polar compounds.

- Atmospheric pressure photoionisation/quadripole/time of flight mass spectrometry (APPI-Q-TOF): adapted for apolar compounds.

Results showed that the molecular weight distribution of a raw asphaltenic fraction obtained in MALDI-TOF is highly dispersed with masses ranging between 100 and $1000 \mathrm{~g} / \mathrm{mol}$ with an average mass of about $380 \mathrm{~g} / \mathrm{mol}$ (Fig. 10) (Merdrignac et al., 2004b). Complementary work showed 


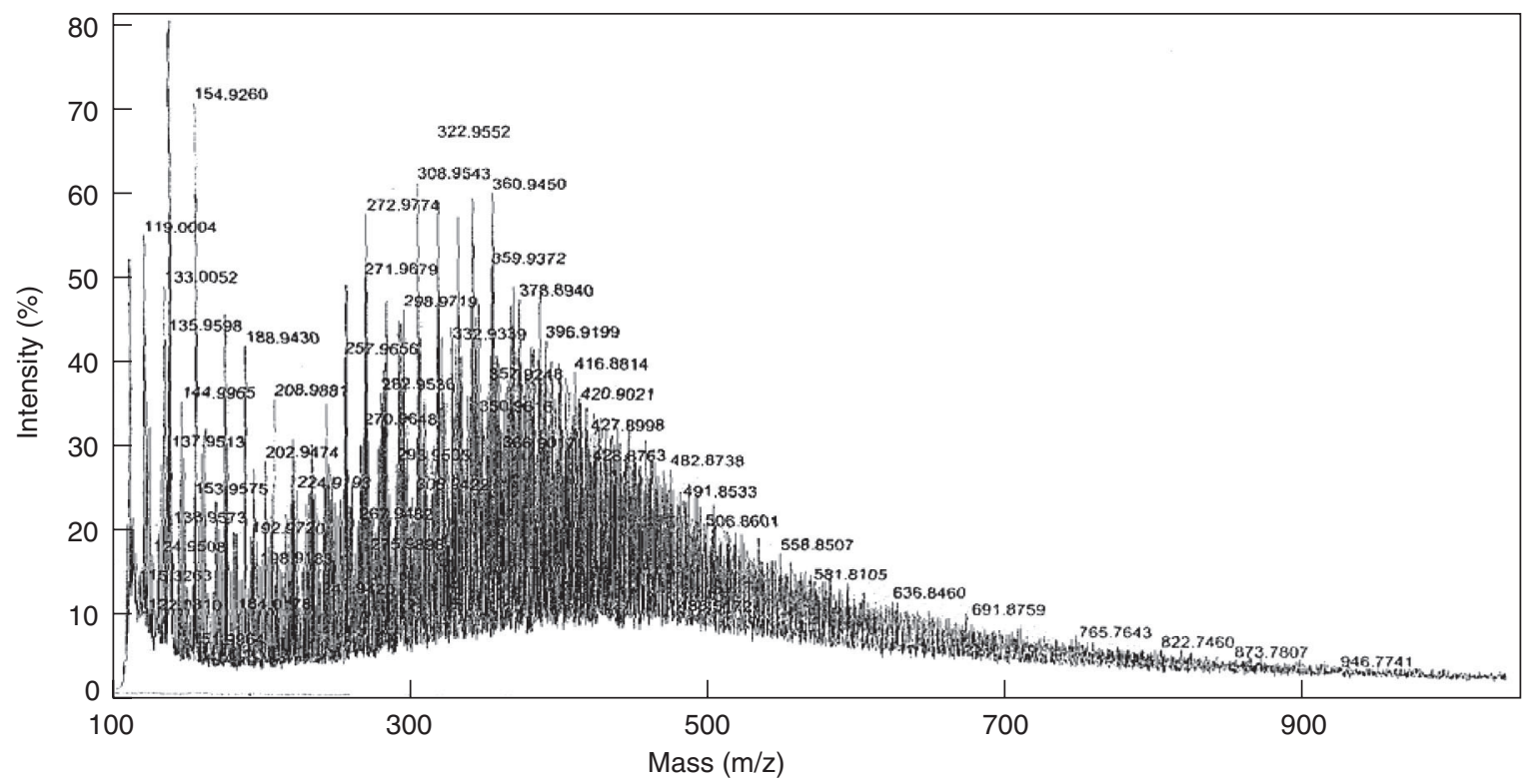

Figure 10

Raw asphaltenes mass spectrum obtained in LDI-TOF (Laser Desorption Ionisation - Time Of Flight), reflexion mode (from Merdrignac et al., 2004b).

that this distribution, too low in masses, does not only result from molecular fragmentation. It would rather come from the high polydispersity of the studied sample, involving analysis discriminations (Merdrignac et al., 2004c). However, much larger mass distributions have been measured on same type of samples by other authors (Herod et al., 2000). They may be due to the formation of dimer, trimer, even polymer structures in the system of ionization (Rodgers et al., 2005).

To decrease the polydispersity of asphaltene is thus an important challenge. Off-line or on-line SEC-MS couplings can be used. To check the coherence of the results, various couplings were tested with SEC-MALDI-TOF, SEC-APCIQ-TOF and SEC-APPI-Q-TOF systems.

Results showed that molecular weight distributions decrease as a function of the elution time (Fig. 11a, b). This indicates that the elution of species is really carried out according to their size in spite of secondary side effects in SEC. Data obtained with the various ionization techniques, showed that they converged with a good agreement toward similar molecular weights. Asphaltene mass profiles ranged between $m / z=350$ and $2000 \mathrm{Da}$ with an average mass between 600 and $700 \mathrm{Da}$ (maximum of SEC peak) according to the technique. Even fractionated, asphaltenes subfractions still remain very complex. Co-elutions and unresolved peaks are predominant in such distributions when analysed with this type of instruments.

To obtain a higher degree of information, authors have used Fourier Transform Ion Cyclotron resonance MS (FTICR MS) using especially electrospray ionisation source. With this very powerful technique of extremely high resolution, more than 10000 compositionally distinct compounds can be resolved enabling assignment of chemical formulas $\left(\mathrm{C}_{\mathrm{C}} \mathrm{H}_{\mathrm{H}} \mathrm{N}_{\mathrm{N}} \mathrm{O}_{\mathrm{O}} \mathrm{S}_{\mathrm{S}}\right)$. Various compounds families like class $\left(\mathrm{N}_{\mathrm{N}} \mathrm{O}_{\mathrm{O}} \mathrm{S}_{\mathrm{S}}\right)$, type $\left(\mathrm{Z}\right.$ in $\left.\mathrm{C}_{\mathrm{C}} \mathrm{H}_{2 \mathrm{c}+\mathrm{Z}} \mathrm{N}_{\mathrm{N}} \mathrm{O}_{\mathrm{O}} \mathrm{S}_{\mathrm{S}}\right)$ and alkylation series may be identified as well. Informations about molecular weight and structural identifications of heavy products can be thus achieved (Qian et al., 2001a; Rodgers et al., 2001; Qian et al., 2001b; Hughey et al., 2002; Marshall et al., 2004; Klein et al., 2006 and literature cited therein).

\subsection{Small Angle Neutron or X-ray Scattering (SANS, SAXS)}

These techniques have been widely used for investigating various colloidal systems (Espinat, 1990; 1991a) and are sensitive to the presence of density fluctuations or heterogeneities. They consist in measuring the radiation scattering intensity $(\mathrm{I}(\mathrm{Q})$, neutron or X-ray) after crossing the sample. This scattering is defined by the scattering vector:

$$
Q=\frac{4 \pi}{\lambda} \sin \theta
$$

where $\theta$ is the angle of observation (deviation from the incident direction) and $\lambda$ is the wavelength of the incident radiation. They allow the measurement of the weight average molecular weight $\left(M_{w}\right)$ and radii of gyration of dispersed colloids. The main differences between the two radiations, $\mathrm{X}$-rays and neutrons, are related to the scattering contrast, their wavelength (close to one angstroem for X-rays and up to 15 angstroems for neutrons) (Espinat, 1990; Espinat et al., 

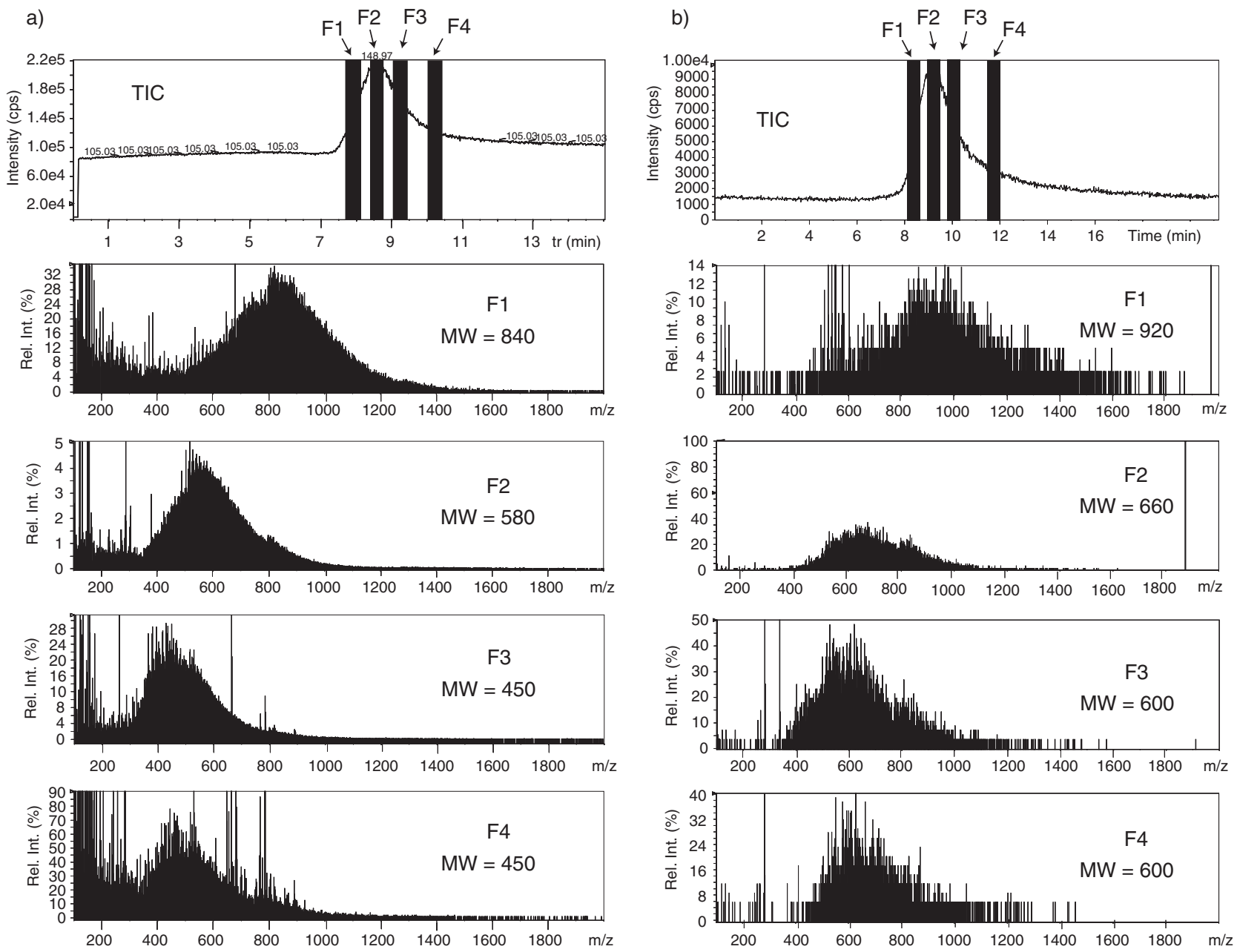

Figure 11

a) SEC-APCI-Q-TOF and b) SEC-APPI-Q-TOF couplings of asphaltene residue. SEC solvent: dichloromethane (from Desmazières et al., 2005).

1998) and the experimental set-up. The use of deuterated solvents for neutron experiments enables a good scattering contrast and consequently a strong scattering intensity. Low concentration measurements can be carried out. SANS experiments need neutrons sources, as for instance in France, the Leon Brillouin Laboratory (LLB-CE Saclay). SAXS measurements can be performed more easily, with classical X-ray laboratory sources (X-ray rotating anode). A great advantage of X-rays is the possibility of investigating natural products as crude oils or heavy fractions (atmospheric or vacuum residues). The range of the scattering vector (Q) explored during experiments is essential because it will determine the range of particle sizes (d) that can be investigated $(d \approx 1 / Q)$. Small angle scattering experiments reveal the spatial structure of particles (asphaltenes) over length scales between a few and several tens (or hundreds in the case of ultra small $\mathrm{X}$-ray scattering (USAXS)) of nanometers.
These techniques are well adapted for colloidal size measurements in heavy fractions like asphaltene molecules dissolved in organic mixtures (Espinat et al., 1998).

Figure 12 illustrates the X-ray scattering of an asphaltene solution (extracted from Safanyia vacuum residue) in toluene. Two main domains can be distinguished:

- the first one at high and intermediate scattering vectors $\left(Q>Q_{1}\right)$ characterized by a nearly constant intensity followed by a strong decrease at higher $Q$;

- the second one, for very low scattering vectors $\left(Q<Q_{1}\right)$ where the scattering intensity rises sharply as $Q$ decreases.

This last domain indicates the presence of large-scale heterogeneities (> 50-100 nanometers) in the solution. The high $Q$ region $\left(Q>Q_{1}\right)$ corresponds to the scattering of single asphaltenic particles or aggregates. This $Q$-range was used for weight average molecular weight $\left(M_{w}\right)$ and radius of gyration $\left(R_{g}\right)$ calculations according to Guinier law (Espinat, 1990; Espinat et al.,1998). Figure 13 exhibits $M_{w}$ and $R_{g}$ 


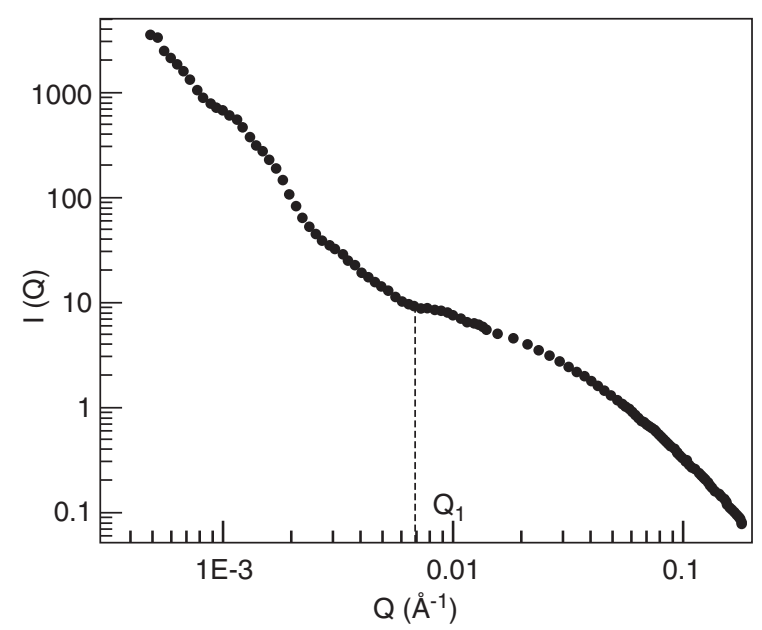

Figure 12

$\mathrm{X}$-ray scattering of Safanyia vacuum residue asphaltenes in solution in toluene $(5.45 \% \mathrm{w} / \mathrm{w})$.

variations as a function of the asphaltene concentration (Espinat et al., 1998; Fenistein, 1998). Three regions can be distinguished:

- for very low concentrations, a decrease of $M_{w}$ and $R_{g}$ appears, but we must highlight that for these concentrations, scattering intensity becomes very low and data treatments are questionable;

- up to $4 \% \mathrm{v} / \mathrm{v}, M_{w}$ and $R_{g}$ remain constant as asphaltene concentration increases;

- above $4 \% \mathrm{v} / \mathrm{v}$, a progressive decrease of $M_{w}$ and $R_{g}$ takes place.
For low concentrations $(<4 \% \mathrm{v} / \mathrm{v})$, asphaltene aggregates are independent in solution, corresponding to the diluted regime, by analogy to polymer solutions behaviour (Fig. 14). The scattering intensity is proportional to the asphaltene concentration. As concentration raises, aggregates become to be in contact, either by steric repulsions (hard sphere interaction) as was recently proposed by Barré et al. (2005), or by overlapping of the asphaltene macromolecules as illustrated in Figure 14 (semi-diluted regime). Thus, the scattering intensity measured for these high concentrations is no longer sensitive to $M_{w}$ and $R_{g}$ but characteristic of a length much smaller than the average size. The threshold concentration delimiting the two regimes is called $\mathrm{C}^{*}$ (Fig. 14) and strongly depends on the origin of the studied asphaltenes and solvent used. Its value is estimated to approximately $4 \%$ in toluene (Fenistein, 1998), but can vary between $2 \%$ (Roux et al., 2001) and 8\% (Sheu et al., 1992) according to the solvent.

Several methods are used for treatment of scattering data, in particular the simulation of the scattering curve using various models of particle shape. When described as discs, cylinders or spheres, asphaltenes can be considered as hard and non-fractal objects. Several authors compared asphaltenes in toluene to cylinder particles (Overfield et al., 1989) but the most general model used is a sphere (Sheu et al., 1992). In other studies, asphaltenes are compared to fractals objects of spherical form (Xu et al., 1995; Roux et al., 2001; Gawrys et al., 2002), discs or oblate cylinders (Thiyagaran et al., 1995; Bardon et al., 1996; Kilpatrick and Gawrys, 2005). In these experimental conditions, the calculated asphaltene radius of gyration may vary from 30 to $200 \AA$, with a corresponding $M_{w}$ ranging between 50000 and $1.10^{6} \mathrm{~g} / \mathrm{mol}$ approximately.
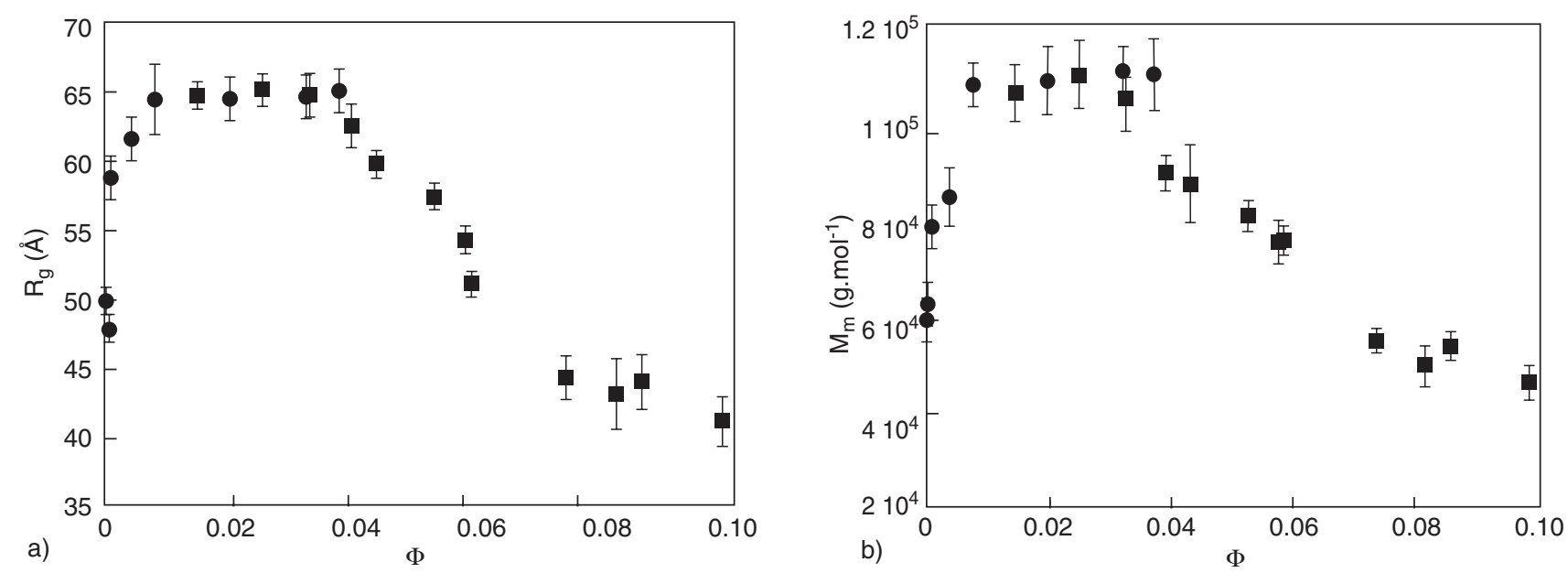

Figure 13

a) Radius of gyration and b) average molecular weight $\mathrm{Mw}$ of Safanyia vacuum residue asphaltenes in toluene solution as a function of asphaltene concentration (from Fenistein, 1998). 


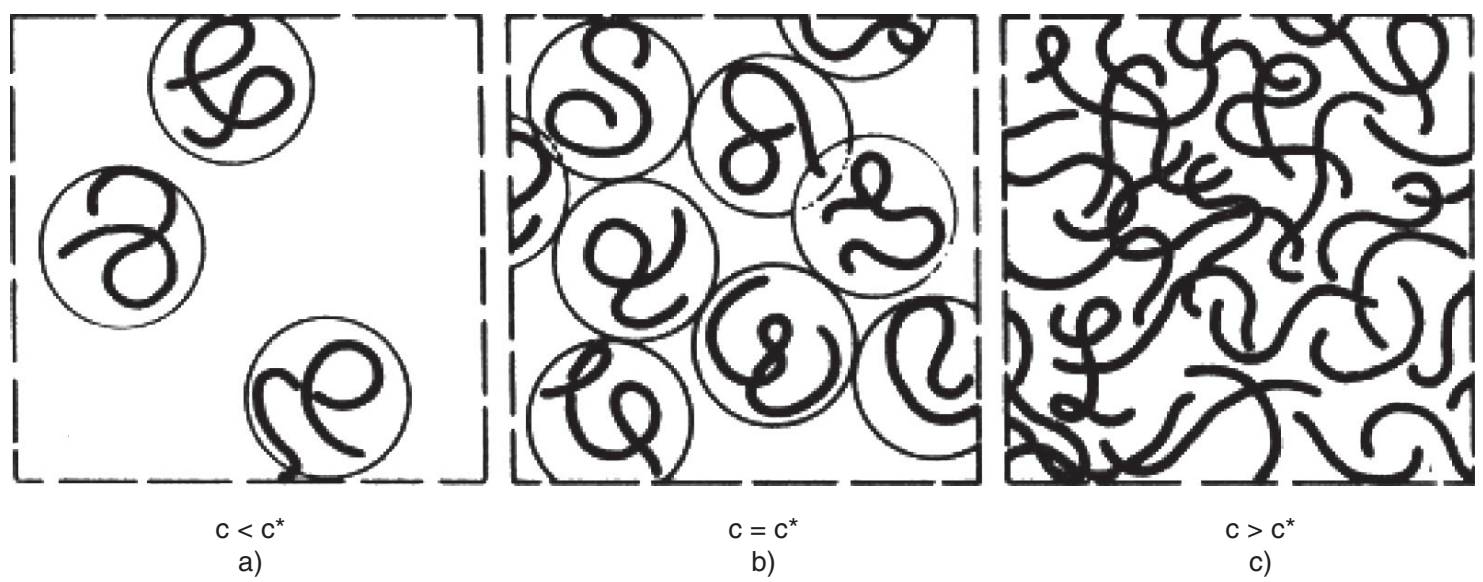

Figure 14

Illustration of a) dilute; b) onset of overlap and c) semi-dilute solutions (from De Gennes, 1979).

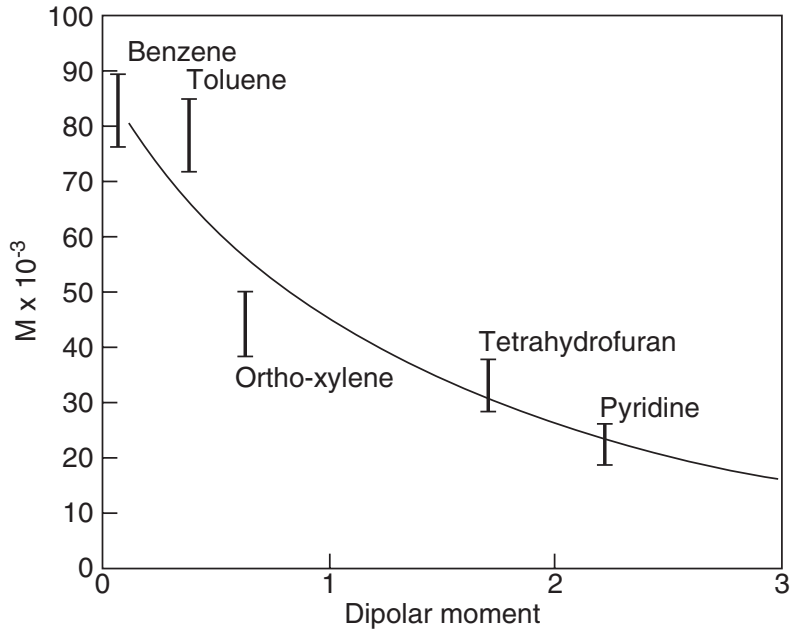

Figure 15

Average molecular weight of Safaniya vacuum residue asphaltenes in solution in various solvents as a function of their dipolar moment.

Actually, the simulation approach does not allow a perfect discrimination between two shape particle models, and a good experimental curve fitting can be obtained considering different models, probably due to the not well defined shape of asphaltene particles and to the large polydispersity.

These structural properties $\left(M_{w}\right.$ and $\left.R_{g}\right)$ are in close relationship with the selected experimental conditions (temperature, dispersive medium, etc.) (Barré et al., 1997). The results showed that the aggregates size decreased with the polarity of the solvent used (Fig. 15) (Ravey and Espinat, 1990; Fenistein et al., 2000; Fenistein and Barré, 2001).
The temperature effect on asphaltene aggregation has also been studied (Fig. 16a, b, Table 4). The results show that a progressive decrease of $R_{g}$ as well as $M_{w}$ of the asphaltene entities are involved when the temperature is increased, even for very high temperatures, close to $563 \mathrm{~K}$ (Ravey et al., 1988; Espinat, 1991b; Fenistein, 1998; Espinat et al., 2004; Tanaka et al., 2003). A temperature decrease is followed by an increase of the size of the asphaltene aggregate up to flocculation (see Fig. 16b).

As previously mentioned, asphaltene macromolecules exhibit a large polydispersity. Preparative size exclusion chromatography has been used for preparing three fractions (Ducouret, 1987), which were investigated by neutron scattering (Ravey et al., 1988) (Fig. 17). A strong decrease of the scattering intensity for small fraction (F4) means a smaller molecular weight (Table 5). We have seen that SEC chromatograms are calibrated by using monodisperse polystyrene polymers. Ducouret (1987) proposed a SEC calibration with molecular weight of each asphaltene fraction (see Table 5). One of the main points of comparison for SAXS or SANS data with SEC results concerns the hydrodynamic volume of each species, asphaltene and polystyrene. Even though, an asphaltene molecule may have the same hydrodynamic volume as a polystyrene polymer, we can suggest that their molecular weight will not be identical. This discussion is still going on.

Ultracentrifugation technique was carried out in order to obtain more or less polydisperse fractions (small (U1) to large (U6) aggregates). The density and the chemical composition of these fractions were determined (Table 6), showing an increase of metal contents (nickel and vanadium) as the molecular weight increases. Scattering intensities of these different asphaltene fractions are shown in Figure 18 and we have observed a rather simple relation between the molecular weight $\left(M_{w}\right)$ and the radius of gyration $\left(M_{w}=27 R_{g}^{2}\right)$ (Fig. 19) (Fenistein, 1998). 

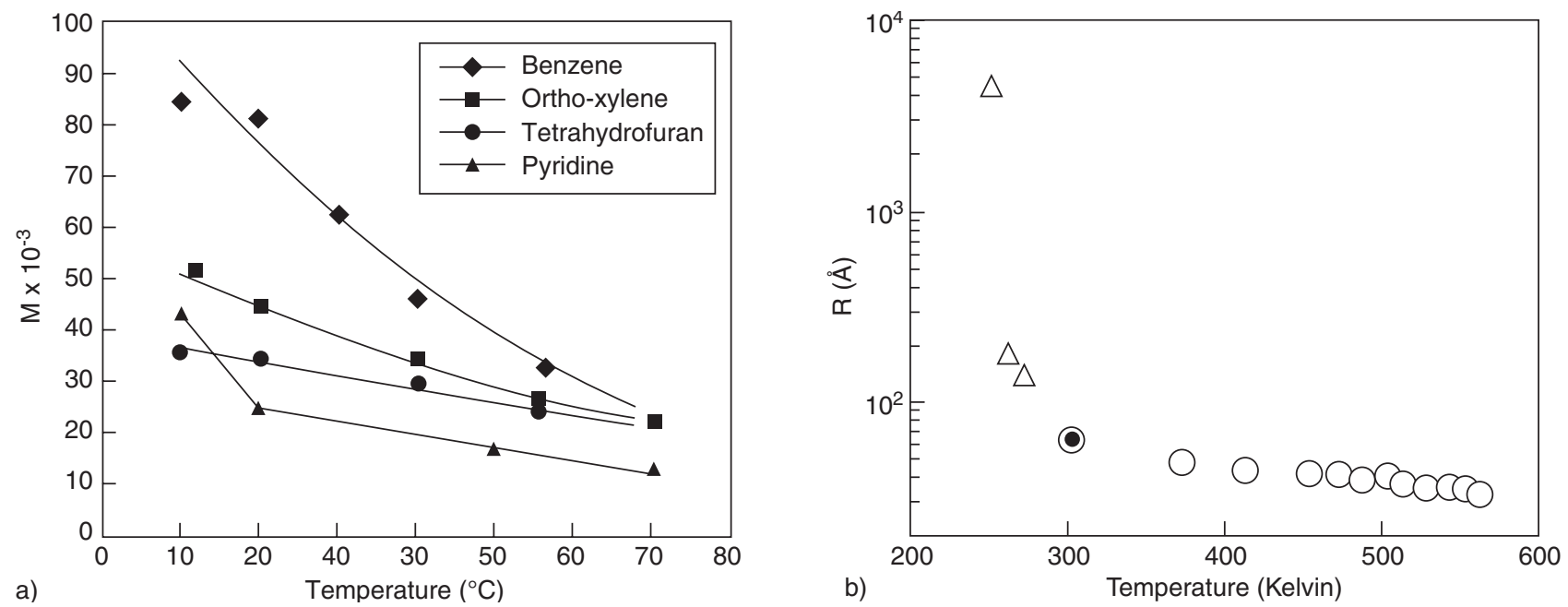

Figure 16

Temperature and solvent effects on asphaltene aggregation: a) average molecular weight $M_{w}$ of Safanyia vacuum residue asphaltenes in solution in different solvents $(\bullet$ tetrahydrofuran, $\boldsymbol{\bullet}$ ortho-xylene, $\bullet$ benzene, $\boldsymbol{\Delta}$ pyridine); b) radii of gyration versus temperature $(\bullet$ SAXS experiments and $\bigcirc$ SANS experiments), $\Delta$ hydrodynamic radii calculated from Photon Correlation Spectroscopy (Light Scattering) for low temperatures (from Espinat et al., 2004).

TABLE 4

Radius of gyration and average molecular weight $\left(M_{w}\right)$ of Safanyia asphaltenes in toluene as a function of temperature (from Espinat et al., 2004)

\begin{tabular}{c|c|c}
\hline Temperature (K) & $\begin{array}{c}\text { Radius of gyration } \\
(\AA)\end{array}$ & $\begin{array}{c}\text { Average Molecular } \\
\text { Weight }(\mathrm{Mw})\end{array}$ \\
\hline 303 & 65 & 115000 \\
373 & 50 & 67000 \\
453 & 45 & 55000 \\
488 & 40 & 43000 \\
563 & 35 & 33000 \\
\hline
\end{tabular}

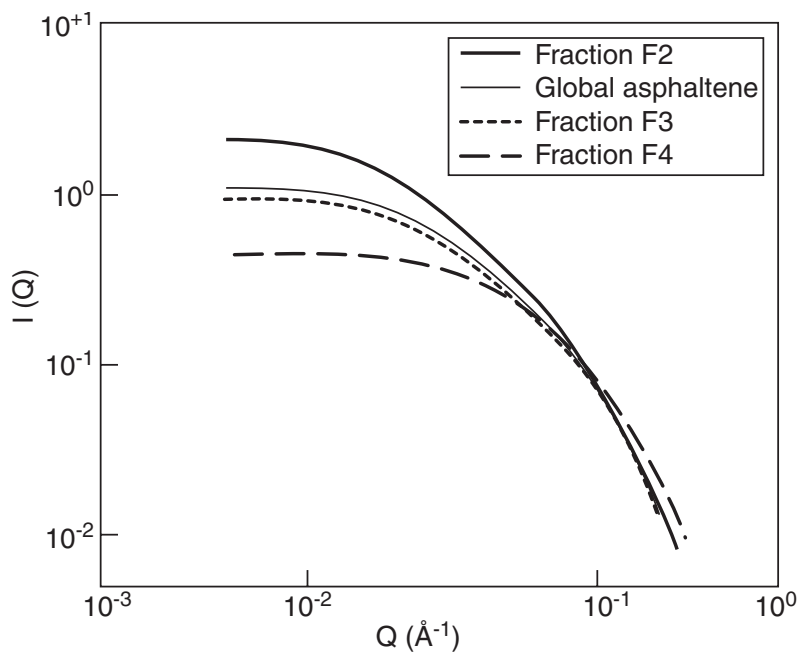

Figure 17

SANS experiments of asphaltene (Safanyia) fractions obtained by SEC fractionation (in tetrahydrofuran) (F2 (large aggregates) to F4 (small aggregates)) (from Ducouret, 1987).
The flocculation process by $n$-heptane addition to the asphaltene solution has been investigated by scattering techniques. The radius of gyration and the average molecular weight $M_{w}$ slowly increase when small $n$-heptane volumes are added to the toluene asphaltene suspension and a strong increase appears when we reach the flocculation threshold (above $45 \% \mathrm{w} / \mathrm{w}$ concentration in n-heptane) (see Table 7) (Fenistein, 1998; Fenistein et al., 1998). Molecular weights and radii of gyration of asphaltene aggregates formed by flocculation process follow the same relationship as observed for ultracentrifugated fractions $\left(M_{w} \approx R_{g}^{2.05}\right)$.

Resins solutions were also studied by SAXS method. Figure 20 displays a comparison of SAXS data for asphaltene and resins of Safanyia vacuum residue. Resins and asphaltene spectra show similarities (see above the description of asphaltene SAXS spectrum), although the intensity scattered by resins is much smaller. The average molecular weight $M_{w}$ of resins was found close to $3500 \mathrm{~g} / \mathrm{mol}$ (Espinat et al., 1998).

An important issue being the characterization of asphaltene in real systems, more experimental data are necessary. Small angle X-ray scattering is probably one of the rare techniques which can be used. Pure Safanyia vacuum residue was studied (Fig. 21) in comparison to its maltenes (soluble part in nheptane). Large heterogeneities (or density fluctuations) exist in the vacuum residue macrostructure (Espinat et al., 1998). Radii of gyration were measured for artificial vacuum residues, made by addition of different amounts of asphaltenes to the recovered maltenes. This was an elegant way to vary the asphaltene concentration in a natural system (Henaut et al., 2001). Rheological properties were also carried out on these artificial materials. Figure 22 displays the gyration radius as compared to the one of the asphaltene in 
TABLE 5

Comparison between SEC and SANS data. Molecular weights and radii of gyration of asphaltene aggregates (fractions F2 to F4) determined by SEC calibrated with monodisperse polystyrenes in tetrahydrofuran solution and SANS (from Ducouret, 1987)

\begin{tabular}{|c|c|c|c|c|}
\hline Asphaltenes & $\begin{array}{c}\text { Molecular weight } \\
\text { in eq. polystyrene (SEC) }\end{array}$ & $\begin{array}{l}\text { Radius of gyration } \\
\text { (̊̊) in eq. polystyrene }\end{array}$ & $\begin{array}{c}\text { Molecular weight } \\
\text { (SANS) }\end{array}$ & $\begin{array}{c}\text { Radius of gyration } \\
\text { (̊) }\end{array}$ \\
\hline $\mathrm{F} 2$ & 29600 & 59 & 77000 & 70 \\
\hline F3 & 22000 & 49.5 & 29000 & 46 \\
\hline F4 & 12500 & 35.5 & 16000 & 30 \\
\hline Asphaltene non fractionated & 18000 & 44 & 33000 & 46 \\
\hline
\end{tabular}

TABLE 6

Chemical composition and density of asphaltene fractions (U1 to U6) obtained by ultracentrifugation

\begin{tabular}{|c|c|c|c|c|c|c|}
\hline Fraction & $\begin{array}{c}\text { Density } \\
\left(\text { kg.m }{ }^{-3}\right)\end{array}$ & $\begin{array}{c}\text { Carbon } \\
(\% \text { w/w })\end{array}$ & $\begin{array}{c}\text { Hydrogen } \\
(\% \text { w/w })\end{array}$ & $\begin{array}{l}\text { Sulphur } \\
(\% \text { w/w })\end{array}$ & $\begin{array}{l}\text { Vanadium } \\
\text { (ppm) }\end{array}$ & $\begin{array}{l}\text { Nickel } \\
\text { (ppm) }\end{array}$ \\
\hline U1 & 1167 & 81 & 8 & 6.81 & 340 & 98 \\
\hline $\mathrm{U} 2$ & 1187 & 82 & 8 & 6.95 & 348 & 97 \\
\hline U3 & 1195 & 82 & 8 & 7.15 & 370 & 99 \\
\hline U4 & 1200 & 82 & 8 & 7.27 & 370 & 102 \\
\hline U5 & 1203 & 82 & 8 & 7.14 & 456 & 138 \\
\hline U6 & 1214 & 82 & 7 & 7.62 & 568 & 184 \\
\hline
\end{tabular}

TABLE 7

Radius of gyration and average molecular weight $\left(M_{w}\right)$ of Safanyia asphaltenes in toluene solution as a function of $n$-heptane addition (From Fenistein, 1998; Fenistein et al., 1998)

\begin{tabular}{c|c|c}
\hline $\boldsymbol{n}$-heptane concentration & Radius of gyration $(\mathbf{\AA})$ & Average molecular weight $(\mathbf{g} / \mathbf{m o l})$ \\
\hline 0 & 61 & 112800 \\
15 & 64 & 132500 \\
35 & 101 & 328600 \\
45 & 199 & 1178600 \\
\hline
\end{tabular}

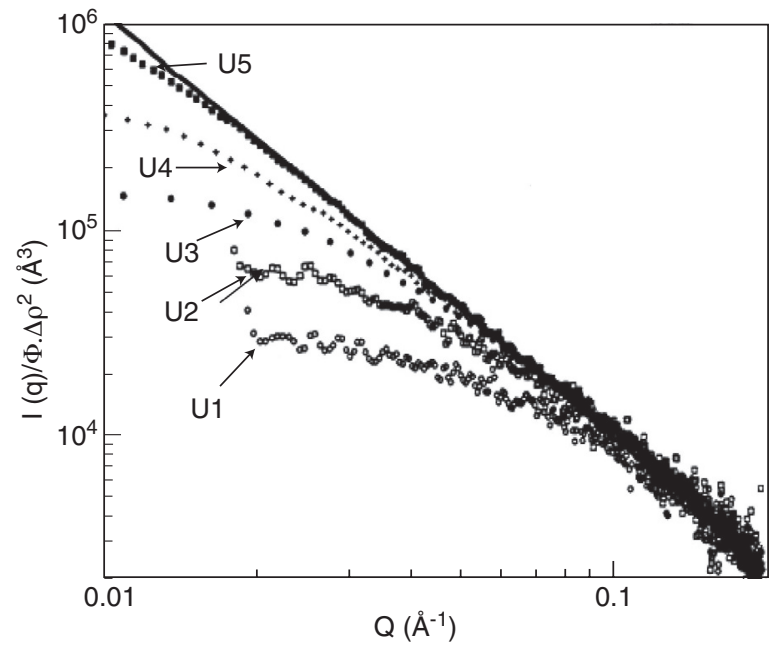

Figure 18

SAXS experiments of asphaltene Safanyia fractions obtained by ultracentrifugation (U1 (small aggregates) to U5 (large aggregates)) (from Fenistein, 1998).

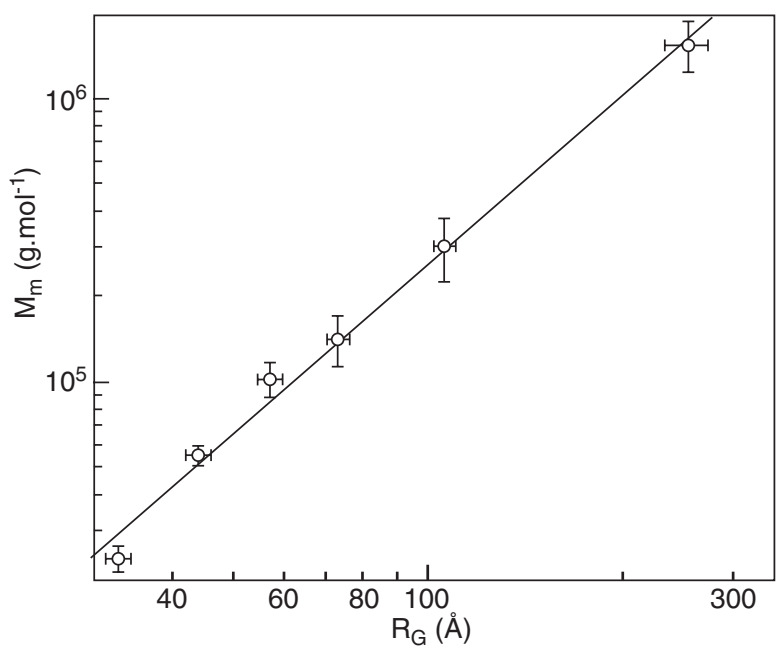

Figure 19

Relation between average molecular weight $M_{w}$ and radius of gyration for Safanyia asphaltenes in toluene solution (from Fenistein, 1998). 


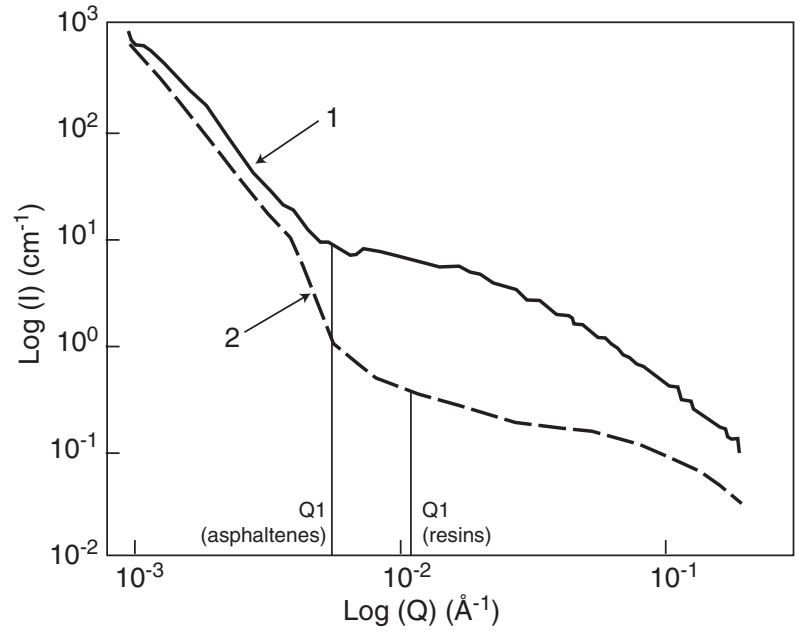

Figure 20

SAXS data obtained for Safanyia (1) asphaltenes and (2) resins in toluene solution $(6 \% \mathrm{w} / \mathrm{w})$ (from Espinat et al.,1998).

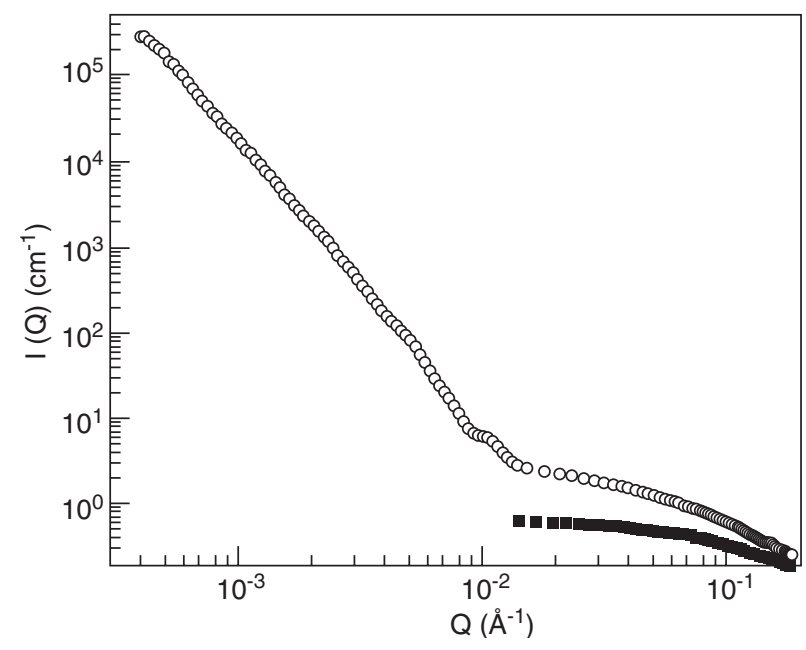

Figure 21

Small angle X-ray scattering of (O) Safanyia vacuum residue and (घ) its maltenes (from Espinat et al., 1998).

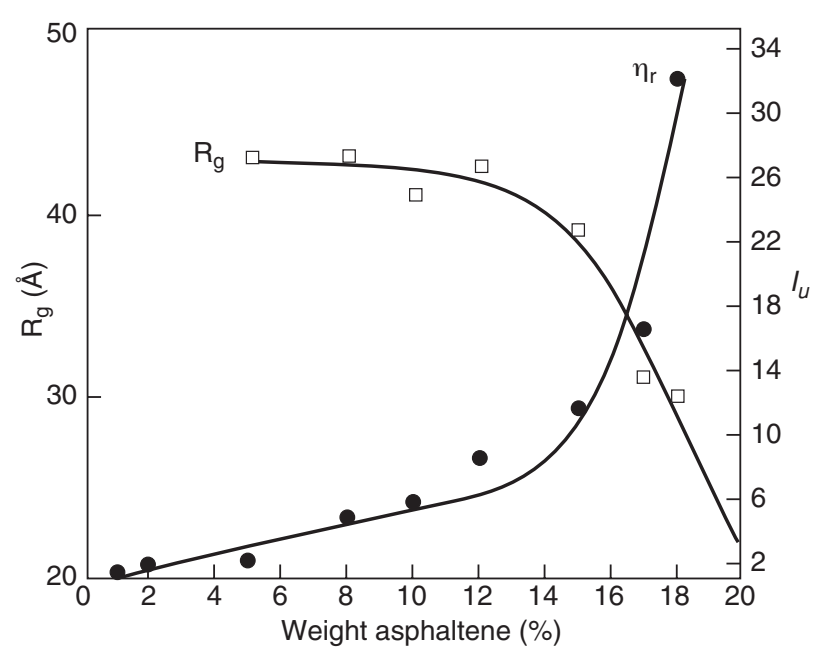

Figure 22

Rheological behaviour compared to SAXS measurements of radius of gyration for pure artificial crude (asphaltenes added to maltenes at different concentrations) (from Henaut et al., 2001).

TABLE 8

Asphaltene molecular weights measured by different analytical methods.

\begin{tabular}{l|c|c}
\hline Analytical method & \multicolumn{2}{|c}{ Average molecular weight $(\mathrm{g} / \mathrm{mol})$} \\
\hline VPO & $\approx 1000-8000$ & $\mathrm{Mn}$ \\
Ebulliometry & $\approx 2500-4000$ & $\mathrm{Mn}$ \\
Cryometry & $\approx 600-6000$ & $\mathrm{Mn}$ \\
GPC & $\approx 1000-1700$ & $\mathrm{Mn}$ \\
& $\approx 6000-13000$ & $\mathrm{Mw}$ \\
MS & $\approx 350-2000$ & $\mathrm{Mw}$ \\
SAXS - SANS & $\approx 50000-1.10^{6}$ & $\mathrm{Mw}$ \\
\hline
\end{tabular}

results of the two techniques. We note a similar behaviour of toluene solution (see Fig. 13). It seems that the macrostructure of asphaltenes in their natural medium is not so far from the one described in a good solvent (toluene). All these data can increase the precision of the aggregation model of asphaltenes in bitumen proposed by Pfeiffer et al. (1940) (Fig. 23).

\subsection{Pulsed Field Gradient Spin-Echo 'H NMR (PFG-' ${ }^{1} \mathrm{H}$ NMR)}

The self-diffusion coefficient $(D)$ is an interesting characteristic from which information on the aggregation state and the molecular weight of studied species in solution can be obtained (Callanghan, 1984; Stilbs, 1987).

PFG- ${ }^{1} \mathrm{H}$ NMR can be applied to complex systems like asphaltenic compounds (Canet et al., 2002). Comparatively fast and applicable to dark mixtures, this technique is used to get information on the geometry of the asphaltenic molecules by measuring the diffusion either of the asphaltenes or of the solvent (Evdokimov et al., 2003; Östlund et al., 2002; 2003; 2004a, b).

Results show that the average diffusion coefficient tends to decrease when the concentration of asphaltenes in solution increases (Johannesson and Halle, 1996; Norinaga et al., 2004). This may be due to obstruction effects which are rationalized by a non-spherical structure. It was proposed that the asphaltenic particles have rather a disc-like shape (Östlund et al., 2001).

\section{CONCLUSION}

Heavy oil fractions are of a very high complexity. This chemical polydispersity is due to the presence of a broad 
a)

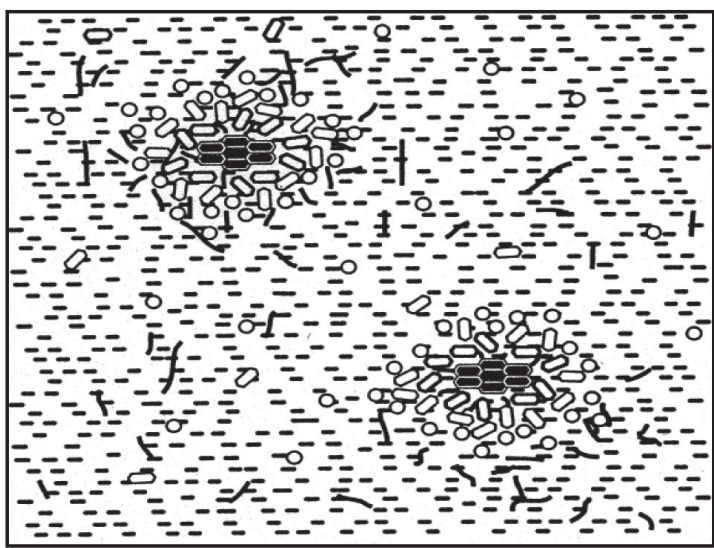

c)

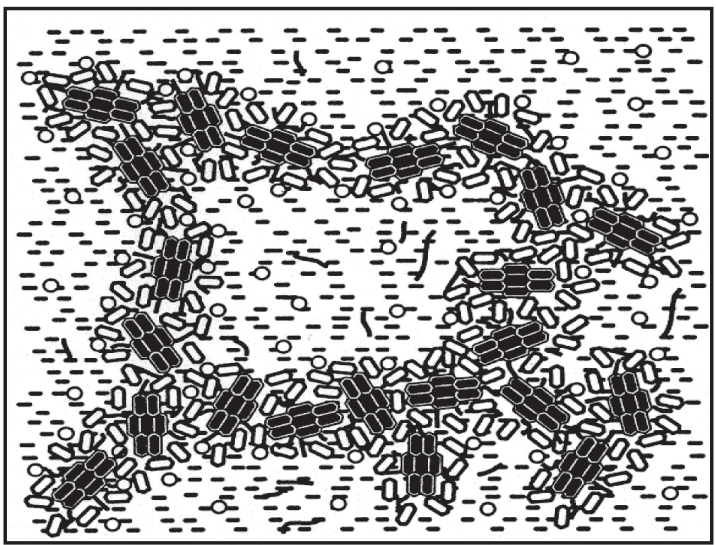

b)

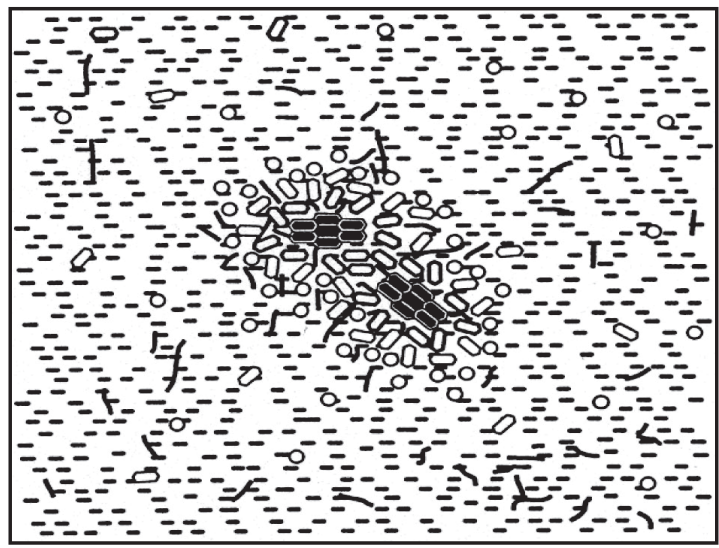

Central part of the asphaltenes
$\begin{aligned} & \text { Compounds of high molecular } \\ & \text { weight and of aromatic nature }\end{aligned}$
$\begin{aligned} & \text { Compounds of lower molecular and of } \\ & \text { a preponderantly aromatic nature }\end{aligned}$
$\begin{aligned} & \text { Compounds of a mixed } \\ & \text { aromatic-naphthenic nature } \\ & \text { Compounds of a mixed } \\ & \text { naphthenic-aliphatic nature } \\ & \text { Compounds of a preponderantly } \\ & \text { aliphatic nature }\end{aligned}$

Figure 23

Illustration proposed by Pfeiffer et al. (1940) of asphaltene molecules in their natural environment (bitumen): a) peptized asphaltenes; b) asphaltene aggregates; c) gel structure due to aggregation.

TABLE 9

Summary of the analytical procedure used for characterization of heavy oil fractions

\begin{tabular}{|c|c|c|c|c|}
\hline \multirow{2}{*}{ Fractionation methods } & \multicolumn{2}{|c|}{ Chemical characterization } & \multicolumn{2}{|c|}{ Colloidal characterization } \\
\hline & Techniques & Information & Techniques & Information \\
\hline $\begin{array}{l}\text { - Boiling point } \\
\text { - Chemical classes } \\
\text { - Degradation } \\
\text { - Solubility }\end{array}$ & $\begin{array}{l}\text { - Pyrolysis - Gas } \\
\text { Chromatography - } \\
\text { Mass Spectrometry } \\
\text { (Py-GC/MS) } \\
\text { - } \text { High Pressure Liquid } \\
\text { Chromatography } \\
\text { (HPLC) } \\
\text { - }{ }^{13} \text { C Nuclear Magnetic } \\
\text { Resonance (NMR) } \\
\text { - Infrared spectroscopy } \\
\text { (IR) } \\
\text { - X-ray Photoelectron } \\
\text { Spectroscopy - } \\
\text { Extended X-ray Fine } \\
\text { Structure - X-ray } \\
\text { Absorption Near Edge } \\
\text { Spectroscopy (XPS - } \\
\text { EXAFS - XANES) }\end{array}$ & $\begin{array}{l}\text { Function groups } \\
\text { Structural motives } \\
\text { Function groups }\end{array}$ & $\begin{array}{l}\text { - Vapor Pressure } \\
\text { Osmometry (VPO) } \\
\text { - Size Exclusion } \\
\text { Chromatography } \\
\text { (SEC) } \\
\text { - Mass spectrometry } \\
\text { (MS) } \\
\text { - Small Angle X-ray and } \\
\text { Neutron Scattering } \\
\text { (SAXS - SANS) } \\
\text { - Pulsed Field Gradient } \\
\text { Spin-Echo NMR (PFG } \\
\text { SE-1H NMR) }\end{array}$ & $\begin{array}{l}\text { MW } \\
\text { Hydrodynamic volume } \\
\text { distribution } \\
\text { MW } \\
\mathrm{R}_{\mathrm{G}} \rightarrow \mathrm{MW} \\
\mathrm{D} \rightarrow \text { hydrodynamic radius }\end{array}$ \\
\hline
\end{tabular}


range of different polarities compounds such as paraffinic, aromatic and heteroatomic molecules. Their main characteristics (high viscosity and significant content of heteroatoms and metals) are in majority related to resins and asphaltenes which constitute the most polar fractions of these oils.

From these high functionalized mixtures, specific properties emerge like self-association/aggregation of asphaltenic structures, involving a tedious characterization. Average structural informations can be obtained. However, they cannot be representative of all the chemical and structural variety that such matrices may contain.

Property measurements of asphaltenes (i.e. MW) strongly depend on the analytical technique performed and the operating conditions used (concentration, temperature, solvent). The asphaltenic structures are not measured in the same aggregation state. This is why the aggregate size of asphaltenes may be different and may vary from several magnetude orders depending on the method used (Table 8).

The analytical scheme generally used to characterize heavy petroleum fractions may be divided into two parts:

- preparative fractionation steps to simplify the initial mixture (too complex for a direct detailed characterization);

- chemical or colloidal characterization (depending on the desired information) applied on fractionated sample.

An illustration of the analytical procedure and the informations obtained is summarized in Table 9 .

\section{REFERENCES}

Akbarzadeh K; Ayatollahi Sh; Nasrifar Kh; Yarranton HW; MoshfeghianM. Oil \& Gas Journal, 51, 2002.

Alboudwarej H; Beck J; Svrcek WY; Yarranton HW; K. Akbarzadeh. Energy\&Fuels, 16, 462, 2002.

Altgelt KH; Boduszynski M. In Composition and analysis of heavy petroleum fractions. Ed Dekker, New York, 1994.

Al-Zaid K; Khan ZH; Hauser A; Al-Rabiah H. Fuel, 77, 5, 453, 1998.

Ancheyta J; Centeno G; TrejoF; Marroquin G; Garcia JA; Tenerio E; Torres A. Energy \& Fuels, 16, 1121, 2002.

Andersen SI. Pet. Sci.technol. 15, 1-2, 185, 1997.

Andersen SI; Keul A; Stenby EH. Pet. Sci. Technol. 17, 7-8, 611, 1997.

Andersen SI; Lira-Galeana C; Stenby EH. Pet. Sci. Technol. 19, 3-4, 457, 2001a.

Andersen SI; Del Rio-Garcia JM; Khvostitchenko D; Shakir S; Lira-Galeana C. Langmuir, 17, 307, 2001b.

Andersen SI; Birdi KS. J. of Colloid and Interface Science, 42, 2 , 1991.

Artok K; Su Y; Hirose Y; Murata S; Nomura M. Sekiyu Gakkaishi, 42, 4, 206, 1999.

Ascanius BE; GarciaDM; Andersen SI . Energy \& Fuels, 18, 1827, 2004.

Aske N; Kallevik H; Sjöblom J . Energy \& Fuels, 15, 1304, 2001. ASTM D893, Annual Book of ASTM Standards, American Society for Testing and Materials.
ASTM D2006, Annual Book of ASTM Standards, American Society for Testing and Materials.

ASTM D2007, Annual Book of ASTM Standards, American Society for Testing and Materials.

ASTM D2887, Annual Book of ASTM Standards, American Society for Testing and Materials.

ASTM D2892, Annual Book of ASTM Standards, American Society for Testing and Materials.

ASTM D3279, Annual Book of ASTM Standards, American Society for Testing and Materials.

ASTM D4124, Annual Book of ASTM Standards, American Society for Testing and Materials.

ASTM D5236, Annual Book of ASTM Standards, American Society for Testing and Materials.

ASTM D6352, Annual Book of ASTM Standards, American Society for Testing and Materials.

Bacaud R; Rouleau L; Cebolla VL; Membrado L; Vela J. Catal. Today, 43, 3-4, 171, 1998.

Bardon C, Barre L, Espinat D, Guille V, Li MH. Fuel Science and technology Int., 14, 203, 1996.

Barman BN. J. Chromatogr. Sci. 34, 219, 1996.

Barre L; Espinat D; Rosenberg E; Scarsella M. Rev. Inst. Fr. Pet., 52, 161, 1997.

Barre L; Palermo T; to be published, 2005.

Bartholdy J; Lauridsen R; Mejlholm M; Andersen SI. Energy \& Fuels, 15, 1059, 2001.

Bertoncini F.; Dulaurent A.; Thiebaud D. To be published, 2005.

Biggs W.R.; Fetzer J.C.; Brown R.J.; Reynolds J.G. Liquid Fuels technology 3, 397, 1985a.

Biggs W.R.; Fetzer J.C.; Brown R.J.; Reynolds J.G. Liquid Fuels technology 3, 423, 1985b.

Billon A; Morel F; Morrison M.E; Peries J.P. Revue de l'Institut Français du Pétrole, 49, 495, 1994.

Boukir A; Guiliano M; Doumùenq P; El Hallaoui A; Mille G. Comptes rendus de l'académie des sciences, série II, fascicule Cchimie 1, 10, 597, 1998.

Brandt HCA; Hendriks EM; Michels MAJ; Visser F. J. Phys. Chem., 99, 10430, 1995.

Brown JK; Ladner WR; Sheppar N. Fuel, 39, 79, 1960.

Brulé B. In Liquids Chromatography of Polymers and related materials II. Eds. J Cazes, X Delamare. M Dekker, 215, 1980.

Buenrostro-Gonzales E; Espinosa-Pena M; Andersen SI; LiraGaleana C. Pet. Sci. Technol. 19, 3-4, 299, 2001.

Buenrostro-Gonzales E; Andersen SI; Garcia-Martinez JA; LiraGaleana C. Energy \& Fuels, 16, 732, 2002.

Bunger J.W.; Li N.C. In Chemistry of asphaltenes, Advances in Chemistry Series 195, American Chemical Society, 1981.

Calemma V; Iwanski P; Nali M; Scotti R; Montanari L. Energy \& Fuels, 9, 2, 225, 1995.

Calemma V; Rausa R; D’Antona P; Montanari L. Energy \& Fuels, 12, 2, 422, 1998.

Callanghan PT. Aust J. Phys., 37, 359, 1984.

Canet D; Boubel JC; Canet-Soulas E. In La RMN, Concepts, méthodes et applications, 2nd edn., Dunod, Paris, 2002.

Cebolla VL; Membrado L; Matt M; Galvez M; Domingo MP. In Analytical Advances for Hydrocarbon Research, CS Hsu Ed., Plenum publishers, New York, Ch 5, 95, 2003.

Cossio FP; Arrieta A;Cebolla VL; Membrado L; Domingo MP; Henrion P. Anal. Chem., 72,1759, 2000. 
Coustet C. PhD. thesis, Université de Bretagne Occidentale, Brest, France. 2003.

Clutter DR; Petrakis L; Stenger RL; Jensen RK. Anal. Chem., 44, 8, 1395, 1972 .

Cunico RL; Sheu EY; Mullins OC. Proc. of Int. Conf. on Heavy Org. Dep., Puerto Vallarta, Mexico, 2002.

Dahan L; Thiebaut D; Bertoncini F; Espinat D; Quignard A. Preprints, ACS, Div. Fuel Chem., 49, 1, 18, 2004.

De Gennes P.G. In Scaling Concepts in Polymer Physics, Cornell University Press, 1979.

Desmazières B; Merdrignac I Terrier P; Delobel A; Laprevote O. Proc. The $6^{\text {th }}$ International Conference on petroleum Phase behavior \& Fouling, Amsterdam, Netherland, June 19-23, 2005.

Domin M; Herrod A; Kandiyoti R; Larsen JW; Lazaro MJ; Li S; Rahimi P. Energy \& Fuels, 13, 552,1999.

Dorbon M; Schmitter JM; Arpino P; Guiochon G. J. Chromatogr., 246, 255, 1982.

Ducouret G; PhD Université Paris VI, 1987.

Durand JP; Petroff N. Collect. Colloq. Semin. (Inst. Fr. Pet.), 40, 200, 1984

Durand JP; Bre A; Beboulene JJ; Ducrozet A; Carbonneaux S. J. Chromatogr. Sci., 36, 9, 431, 1998.

Dutta TK; Harayama S. Anal. Chem., 73, 5, 864, 2001.

Ehrmann U; Izquierdo A. Fuel Sci. Technol. Int., 12, 9, 1193 , 1994.

Espinat D. Rev. Inst. Fr. Pet., 45, 6, 775, 1990.

Espinat D. Rev. Inst. Fr. Pet, 46, 5, 595, 1991a.

Espinat D. Rev. Inst. Fr. Pet, 46, 6, 759, 1991b.

Espinat D; Rosenberg E; Scarsella M; Barre L; Fenistein D; Broseta D. In Structures and Dynamics of Asphaltenes, O. C. Mullins and E.Y. Sheu (Eds.), Plenum Press, 145, 1998.

Espinat D., Fenistein D., Barré L., Frot D., Briolant Y., Energy \& Fuels, 18, 1243, 2004.

Evans DF; Wennerström. In The Colloidal Domain, 2nd edn., Wiley, New York, 1998.

Evdokimov IN; Eliseev NY; Akhmetov BR. Fuel, 82, 817, 2003.

Favre A; PhD. Université Paris VI, France, 1984.

Feeney MJ; Huber L. Collect. Colloq. Semin. (Inst. Fr. Pet.), 40, 206, 1984.

Feillens MT; Leroux B; Bourgognon H. Collect. Colloq. Semin. (Inst. Fr. Pet.), 40, 212, 1984.

Fenistein D. PhD. Université Paris VI, France, 1998.

Fenistein D.; Barré L.; Broseta D.; Espinat D.; Livet A.; Roux J.N.; Scarsella M. Langmuir, 14, 1013, 1998.

Fenistein D; Barre L; Frot D. Oil \& Gas Sci. and Technol, 55, 123, 2000.

Fenistein D; Barre L. Fuel, 80, 283, 2001.

Fetzer JC; Kershaw JR. Fuel, 74, 10, 1533, 1995.

Fish R.H.; Komlenic J.J.; Brian K. Wines. Anal. Chem. 56, 2452, 1984.

Gawrys KL; Spiecker PM; Kilpatrick PK. Preprints, ACS, Div Pet. Chem., 47, 4, 332, 2002.

Gorbaty ML; Kelemen SR. Fuel Process. Technol. 71, 71, 2001.

Goulon J.; Retournard A.; Friant P.; Goulon-Ginet C.; Berthe C.; Muller J.F.; Poncet J.L.; Guilard R.; Escalier J.C.; Neff B. J. Chem. Soc. Dalton Trans. 1095, 1984.

Green JB; Hoff RJ; Woodward PW; Stevens LL. Fuel, 63, 1290, 1984.
Green JB; Stierwalt BK; Green JA; Grizzle PL. Fuel, 64, 1571, 1985.

Green JB; Reynolds JW; Yu SKT. Fuel Sci. Tech. Int., 7, 1327, 1989.

Groenzin H; Mullins OC. Energy \& Fuel, 14, 677, 2000.

Guibard I; Merdrignac I; Kressmann S. In Heavy Hydrocarbon Resources: Characterization, Upgrading and Utilization, American Chemical Society, Symposium Series 895, Ed. M Nomura, Oxforf Univ., Chapter 4, 51, 2004.

Haaland O; Klovning R; Sem T. Preprints, 7th UNITAR Int. Conf. Heavy Crude and Tar Sand. 1, Paper 1998-008, 73, 1998.

Hamid SH. Pet. Sci. technol. 18, 871, 2000.

Hammami A; Ferworn KA; Nighswander JA; Overa S; Stange E. Pet. Sci and Tech., 16, 227, 1998.

Hatrik S; Lehotay J. J. Liq. Chromatogr. 17, 13, 2733, 1994.

Herod AA; Lazaro MJ; Domin M; Islas CA; Kandiyoti R. Fuel, 79, 323, 2000.

Henaut I.; Barre L.; Argillier J.F.; Brucy F.; Bouchard R. SPE Int. Symp. on Oilfield Chemistry, pap 65020, Houston, Texas, February 2001.

Hughey CA; Rodgers RP; Marshall AG. Anal. Chem., 74, 4145, 2002.

Ibrahim YA; Abdelhameed MA; Al-Sahhaf TA; Fahim MA. Pet. Sci.technol. 21, 825, 2003.

Ignatiadis I; Schmitter JM; Arpino P. J. Chromatogr., 324, 87, 1985.

Johannesson H; Halle B. J Chem. Phys., 104, 17, 6807, 1996.

Kiet HH; Malhotra SL; Blanchard LP. Anal. Chem., 50, 1212, 1978.

Kilpatrick PK; Gawrys KL. Preprints The 6th International Conference on petroleum Phase behavior \& Fouling, Amsterdam, Netherland, June, 2005.

Kim S; Branthaver JK. F. Sci. \& Technol. Intl. 14, 365, 1996.

Klein GC; Rodgers RP; Marshall AG. Fuel, 85, 2071, 2006.

Kodal SL; Sayegh SG. J. Can. Pet. Tech., 29, 77, 1990.

Kodera Y; Kondo T; Saito I; Okegawa K. Energy \& Fuels, 14, 291, 2000.

Kowalewski I.; Vandenbroucke M.; Huc A.Y.; Taylor M.J.; Faulon J.L. Energy \& Fuels 10, 97, 1996.

Leon O; Rogel EJ; Espidel J; Torres GA. Energy \& Fuels, 14, 6, 2000.

Lin-Vien D; Colthup NB; Fateley WG; Grasseli JG. In Handbook of Infrared and Raman Characteristic Frequencies of Organic Molecules. Academic Press, San Diego, 1991.

Mannistu KD; Yarranton HW; Masliyah JH. Energy \& Fuels, 11, 615, 1997.

Marshall AG; Rodgers RP. Acc. Chem. Res., 37, 53, 2004.

Masuda K; Okuma O; Nishizawa T; Kanaji M; Matsumura T. Fuel, 75, 3, 295, 1996.

Matt M; Galvez EM; Cebolla VL; Membrado L; Bacaud R; Pessayre S. J. Sep. Sci., 26, 1665, 2003.

McCaffrey WC; Sheremata JM; Gray MR; Dettman H. Proc. The 4th International Conference on petroleum Phase behavior \& Fouling, Trondheim, Norway, June 2003.

Mc Kay JF; Weber JM; Latham DR. Anal. Chem. 48, 891, 1976.

Mc Kay JF; Amend PJ; Harsberger; Cogswell TE; Latham DR. Fuel, 60, 14, 1981.

Merdrignac I. PhD, Université Louis Pasteur, Strasbourg, France, 1997. 
Merdrignac I; Béhar F; Briot P; Vandenbroucke M; Albrecht P. Energy \& Fuels, 12 (6), 1342, 1998.

Merdrignac I; Truchy C; Robert E; Guibard I; Kressmann S. Pet. Sci.technol. 22, 7-8, 1003, 2004a.

Merdrignac I; Desmazières B; Laprevote O; Terrier P. Preprints AICHE 2004 Spring National Meeting, div. Analysis/ Characterization April, New Orleans, LA, USA, 2004b.

Merdrignac I; Desmazières B; Terrier P; Delobel A; Laprevote O. Proc. of Int. Conf. on Heavy Org Dep, Los cabos, Baja California, Mexico, Nov., 2004c.

Merino-Garcia D.; Andersen SI. Pet. Sci. Techn., 21, 507, 2003.

Merino-Garcia D.; Andersen SI. Langmuir, 20, 1473, 2004a.

Merino-Garcia D.; Andersen SI. Langmuir, 20, 4559, 2004b.

M'Hamdi R; Thiebaut D; Caude MJ. High Resolut. Chromatogr., 20, 10, 545, 1997.

Mitra-Kirtley S; Mullins OC; Van Elp J; George SJ; Chen J; Cramer SP. J. Am. Chem. Soc. 115, 252, 1993.

Monin JC; Vignat A. Rev. Inst. Fra. Pet. 39, 6, 821, 1984.

Morel F; Kressmann S; Harlé V; Kasztelan S. In Hydrotreatment and hydrocracking of oil fractions, Eds. G.F. Froment, B. Delmon and P. Grange, Elsevier Science, 1, 1997.

Moschopedis SE; Speight JG. Fuel, 55, 334, 1976.

Moschopedis SE; Fryer JF; Speight JG. Fuel, 55, 184, 1976.

Murgich J, Rodriguez JM; Aray Y. Energy \& Fuels, 10, 68, 1996.

Murgich J; Merino-Garcia D; Andersen SI.; del Rio JM; Lira Galeana C. Langmuir, 18, 9080, 2002.

Murgich J. Molecular Simulations 29, 451, 2003.

Murgich J. Proc. The 6th International Conference on petroleum Phase behavior \& Fouling, Amsterdam, Netherlands, June, 2005.

Nali M; Calemma V; Montanari L. Org. Mass. Spectrom. 29, 11, 607, 1994.

Nalwaya V; Tangtayakom V; Piumsomboon P; Fogler S. Ind. \& Eng. Chem. Res., 38, 3, 964, 1999.

Neer OA; Deo MD. J. Chromatogr. Sci., 33, 3, 133, 1995.

Neves GBM; De Sousa MD; Travalloni-Louvisse AM; Lucas EF; Gonzales G. Pet. Sci. Technol. 19, 1-2, 35, 2001.

Nishioka M; Tomich RS. Fuel, 72, 1007, 1993.

Norinaga K; Wargardalam VJ; Takasugi S; Iino M; Matsukawa S. Energy \& Fuels, 18, 531, 2004.

Oka M., Chang H.C., Gaualas G.R. Fuel, 56, 3, 1977.

Östlund JA; Andersson SI; Nyden M. Fuel, 80, 1529, 2001.

Östlund JA; Löfroth JE; Holmberg K; Nyden M. J of Coll and Interface Sci, 253, 150, 2002.

Östlund JA; Nyden M; Auflem IH; Sjöblom J. Energy \& Fuels, 17, 113, 2003.

Östlund JA; Wattana P; Nyden M; Fogler HS. J of Coll and Interface Sci, 271, 2, 372, 2004a.

Östlund JA; Nyden M; Stilbs P. Energy \& Fuels, 18, 531, 2004b.

Overfield RE; Sheu EY; Sinha SK; Liang KS. Fuel Sci. and Technol. Int., 7, (5-6), 611, 1989.

Payant JD; Mojelsky TW; Strausz OP. Energy \& Fuels, 3, 449, 1989.

Peng DT; Robinson DB. Ind. and Eng. Chem. Fundamental., 15, 59, 1976.

Peramanu S; Pruden BB. Ind. Eng. Chem. Res., 38, 8, 3121, 1999.

Pfeiffer JP.; Saal RN. Journal of Physical Chemistry, 44, 139, 1940.
Qian K; Rodgers RP; Hendrickson CL; Emmett MR; Marshall AG. Energy \& Fuels, 15, 492, 2001a.

Qian K; Robbins WK; Hughey CA; Cooper HJ; Rodgers RP; Marshall AG. Energy \& Fuels, 15, 1505, 2001b.

Ravey JC; Ducouret G.; Espinat D. Fuel, 67,245, 1988.

Ravey JC; Espinat D. Progress in Colloid \& Polymer Sci. 81, 127, 1990.

Reddy KM; Wei B; Song C. Catal. Today, 43, 3-4, 187, 1998.

Rietjens M; Nieuwpoort M. Fuel, 80, 33, 2001.

Robins C; Limbach PA. Rapid Commun. Mass Spectrom., 17, 24, 2839, 2003.

Rodgers RP; Hendrickson CL; Emmett MR; Marshall AG; Greabey M; Qian K. Can. J. Chem., 79, 546, 2001.

Rodgers RP; Purcell JM; Schaub TM; Marshall AG. Preprints The 6th International Conference on petroleum Phase behavior \& Fouling, Amsterdam, Netherland, June, 2005.

Rogel EJ. Energy \& Fuel, 14, 566, 2000.

Roux JN; Broseta D; Demé B. Langmuir, 17, 5085, 2001.

Satya S. Proc. Int. Conf. on Heavy Orgs Dep, Los cabos, Baja California, Mexico, Nov. 2004.

Sarret G; Connan J; Kasrai M; Bancroft GM; Charie-Duhaut A; Lemoine S; Adam P; Albrecht P; Eybert-Berard L. Geochim. Cosmochim. Acta., 63, 22, 3767, 1999.

Schwartz HE. J. Chromatogr. Sci., 26, 275, 1988.

Shariff SM; Tong D; Bartle KD. J. Chromatogr. Sci., 32, 541, 1994.

Sharma BK; Sarowha SLS; Bhagat SD; Tirawi RK; Gupta SK; Venkataramani PS. Fres. J. of Anal. Chem., 360, 5, 539, 1998.

Sharma BK; Sarowha SLS; Bhagat SD; Tirawi RK; Gupta SK; Venkataramani PS. Pet. Sci \& Technol., 17, 3-4, 319, 1999.

Sharma BK; Stipanovic A; Tyagi OS . Preprints ACS, $220^{\text {th }}$ Nat. Meet., Div. Petr. Chem., 45, 4, 643, August 2000a.

Sharma BK; Tyagi OS; Aloopwan MKS; Bhagat SD. Pet. Sci. technol. 18, 3-4, 249, 2000b.

Sheu EY; Storm DA; De Tar MM. J. Non-Crystalline Solids. 347, $131,1991$.

Sheu EY; De Tar MM; Storm DA. DeCanio J. Fuel, 71, 299, 1992.

Sheu EY; Liang KS; Sinha SK; Overfield RE. J. of Coll. and Interface Sci., 153, 2, 399, 1992.

Sheu EY. Energy \& Fuels, 16, 74, 2002.

Shi TP; Hu YX; Xu ZM; Su T; Wang RA. Ind. Eng. Chem. Res., 36, 9, 3988, 1997.

Simoneit BR; Fetzer JC. Org. Geochem, 24, 10-11, 1065, 1996.

Singh ID; Ramaswami V; Kothiyal V; Brouwer L; Severin D. Fuel Sci.Tech. Int., 10, 2, 267, 1992.

Speight JG; Wernick DL; Gould KA; Overfield RE; Rao BML; Savage DW. Rev. Inst. Fra. Pet. 40, 1, 51, 1985.

Speight JG. In The Chemistry and Technology of Petroleum, Marcel Dekker Inc., New York, 1999.

Srinivasan NS. Fuel Process. Technol., 43, 2, 129, 1995.

Stilbs P. Prog NMR Spectrosc, 19, 1, 1987.

Strausz OP; Mojelsky TW; Lown EM. Fuel, 71, 1355, 1992.

Strausz OP; Mojelsky TW; Lown EM; Kowalewski I; Behar F. Energy \& Fuels, 13, 3, 228, 1999 (a). 
Strausz OP; Mojelsky TW; Faraji F; Lown EM; Peng P. Energy \& Fuels, 13, 3, 207, 1999 b.

Strausz OP; Peng P; Murgich J. Energy \& Fuel, 16, 809, 2002.

Strausz OP; Lown EM. In The Chemistry of Alberta Oil Sands, Bitumen and heavy Oils. AERI, Calgari, 2003.

Su Y; Artok L; Murata S; Nomura M. Energy \& Fuels, 12, 6, $1265,1998$.

Szewczyk V; Behar F; Behar E; Scarsella M. Rev. Inst. Fra. Petr, $\mathbf{5 1 , ~ 4 , ~ 5 7 5 , ~} 1996$.

Tanaka R; Sato S; Takanohashi T; van Wermeskerken N; Hunt JE; Winans RE. Preprints, 52th Can. Chem. Eng. Conf., 2002.

Tanaka R; Hunt JE; Winans RE; Thiyagarajan P. Energy \& Fuels, 17, 127, 2003.

Thiyagaran P; Hunt JE; Winans RE; Anderson KB; Miller JT. Energy \& Fuels, 9, 829, 1995.

Tissot B. Rev. Inst. Fra. Pet. 36, 4, 429, 1981.
Wattana P; Fogler HS; Yen A; Del Carmen Garcia M;Carbognani L. Proc of Int. Conf. on Heavy Org. Dep., Puerto Vallarta, Mexico, Nov., 2002.

Wilhems A; Larter SR; Schulten HR. Org. Geochem., 20, 7, 1049, 1993.

Xu Y; Koga Y; Strausz OP. Fuel, 74, 960, 1995.

Yan X; Wu Y; Sun Y. J. Chromatogr. A. 17, 1-2, 337, 1996.

Yarranton HW; Beck L; Alboudwarej H; Svrrcek WY. ACS, Div. Petrol. Chem., 47, 4, 336, 2002.

Yen TF; Erdman JG; Pollack SS. Anal. Chem, 33, 1587, 1961.

Yen TF. In Encyclopedia of polymer science and Engineering, Eds. M Grayson and JJ Krochwitz, 1988.

Yen TF. In Structures and Dynamics of Asphaltenes, Eds. O Mullins and EY Sheu, Plenum, New York, 1998.

Final manuscript received in November 2005 